Universidad de Lima

Facultad de Psicología

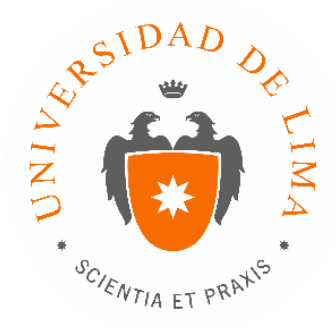

\title{
USO DE LOS CELULARES CON INTERNET Y RENDIMIENTO ACADÉMICO DE ESTUDIANTES UNIVERSITARIOS
}

Tesis para optar por el título profesional de Licenciado en Psicología

Ciara Paola Cuba Alvarado

Código 20080292

\author{
Asesor \\ Vicente Rodríguez Salcedo
}

Lima - Perú

Diciembre de 2016 


\section{USO DE LOS CELULARES CON INTERNET Y RENDIMIENTO ACADÉMICO DE ESTUDIANTES UNIVERSITARIOS}




\section{TABLA DE CONTENIDO}

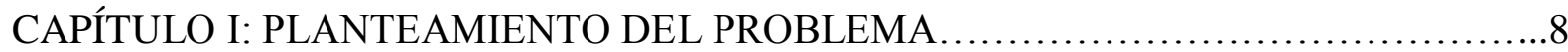

1.1 Descripción del problema.............................................8

1.2 Justificación y relevancia..................................................... 11

CAPÍTULO II: MARCO TEÓRICO................................................. 14

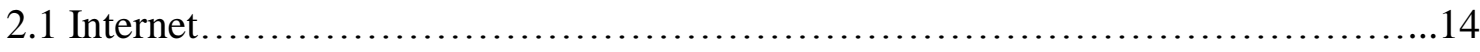

2.1.1 Definición de Internet........................................... 14

2.1.2 Uso y abuso del Internet.......................................... 14

2.1.3 Consecuencias del uso y abuso del Internet...............................19

2.1.4 Definición de Smartphones.........................................20

2.1.5 Uso y abuso de los Smartphones.........................................21

2.1.6 Consecuencias del uso y abuso de los Smartphones.........................28

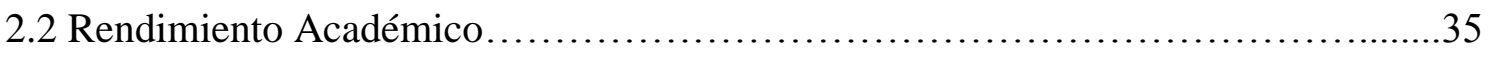

2.2.1 Definición de Rendimiento Académico...................................35

2.2.2 Relación entre Rendimiento Académico y Smartphones.............................35

2.2.3 Consecuencias del uso de los Smartphones en el Rendimiento Académico.....36

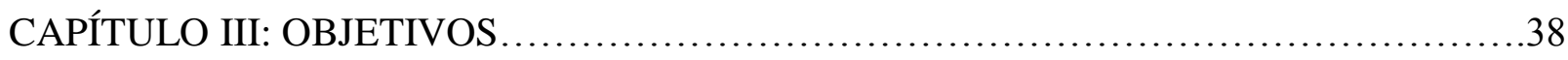

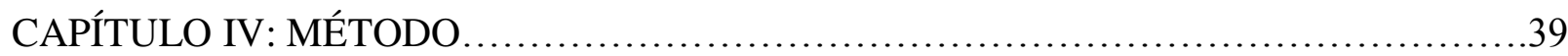

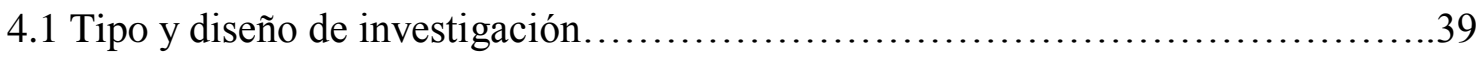

4.2 Participantes......................................................... 40

4.3 Técnicas de recolección de datos......................................42

4.4 Procedimiento de recolección de datos..................................42

4.5 Estrategias de análisis de datos........................................43

CAPÍTULO V: RESULTADOS Y DISCUSIÓN ....................................45

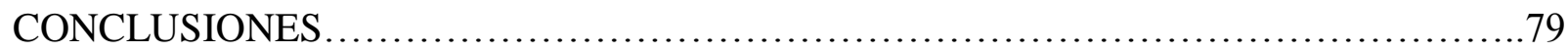

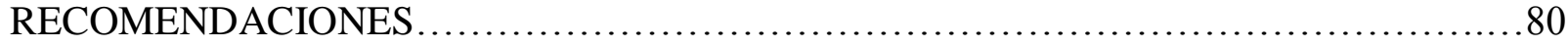

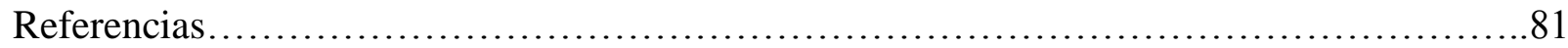




\section{ÍNDICE DE ANEXOS}

Anexo 1: Guía de Entrevista Semi Estructurada.......................................84

Anexo 2: Libro de Códigos....................................................86

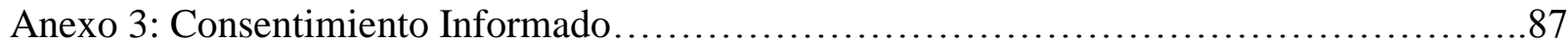




\section{RESUMEN}

Actualmente los Smartphones se han convertido en un elemento indispensable para la vida cotidiana, ya que cuenta con aplicaciones que hoy son un boom, especialmente para los jóvenes. El presente estudio tiene como objetivos: conocer las consecuencias del uso del Smartphone en el rendimiento académico de los estudiantes, identificar las razones que generan la necesidad de utilizar constantemente el celular, describir la influencia del Smartphone en su rendimiento académico y finalmente, identificar si el uso del Smartphone es percibido como beneficioso o perjudicial por los estudiantes en el rendimiento académico. Es un estudio de tipo exploratorio y descriptivo, utilizando el método fenomenológico. Se utilizó como instrumento una entrevista semiestructurada con 37 preguntas guía que se aplicó a una muestra de 15 estudiantes, de ambos géneros, de edades entre 21 y 24 años, pertenecientes a diversas universidades de Lima Metropolitana, que se encuentren en los últimos cuatro ciclos de sus estudios. Como resultado se obtuvo que los estudiantes perciben que el uso del Smartphone, si bien no afecta en su promedio académico, sí afecta en el tiempo que dedican para estudiar o hacer actividades académicas; es decir, lo perciben como beneficioso por un lado y perjudicial por otro.

Palabras Clave: Rendimiento Académico, Celular, Smartphone. 


\begin{abstract}
Currently the Smartphones have become something indispensable to everyday life, since it has applications that today are a boom, especially for the young people. The objectives of this research are to know the consequences of using the Smartphone in students' academic performance, to identify the reasons for the need to constantly use the cell phone, to describe the influence of the Smartphone on academic performance and finally to identify if using the Smartphone is perceived as beneficial or detrimental by students in academic performance. This is an exploratory and descriptive study, using the phenomenological method. A semistructured interview with 37 guiding questions was used as an instrument, which was applied to a sample of 15 students of both genders, between 21 to 24 years old, belonging to several universities of Lima Metropolitan, coursing in the last four cycles of his studies. As a result, students perceive that the use of the Smartphone, although it doesn't affect in their academic average, does affect in the time that they dedicate to study or to do academic activities; that it, perceived as beneficial on one hand and harmful on the other.

Key Words: Academic Performance, Cell phone, Smartphone.
\end{abstract}




\section{CAPÍTULO I: PLANTEAMIENTO DEL PROBLEMA}

\subsection{Descripción del Problema}

En la actualidad muchos jóvenes estudiantes pertenecientes a niveles socioeconómicos A y B, principalmente, poseen como mínimo un celular, y en el mejor de los casos un celular con servicio de internet; sea este un IPhone, Android, entre otros (Smartphones); el cual utilizan constantemente y muchas veces durante grandes cantidades de tiempo. A partir de ello, el problema planteado vendría a ser las consecuencias de este uso que se le da al Smartphone, o en todo caso abuso de éste, en el rendimiento académico de estudiantes universitarios. Esto es un problema, ya que estas consecuencias podrían estar llevando a actitudes y/o conductas dependientes, que estarían interfiriendo en el ámbito académico en el que se encuentran dichos estudiantes.

Además, el uso frecuente y sin pausas de los celulares con internet pueden causar en el transcurso del tiempo, en un futuro no muy lejano, problemas en las articulaciones de los dedos (por teclear en un espacio sumamente reducido), en la visión (por estar mirando la pantalla con letras pequeñas y al caer la iluminación de esta en los ojos), en el sueño (ya que se ha comprobado que muchos usuarios mantienen sus celulares prendidos todo el tiempo y no suelen apagarlos ni para dormir, sino por el contrario, inclusive si éste suena mientras duermen, ellos despiertan y responden los mensajes o llamadas), etc.

Justamente, los problemas antes mencionados se pueden notar en la falta de seguridad en uno mismo, incapacidad para relacionarse con otros, dependencia, estrés y ansiedad son posibles factores para desencadenar la adicción a dicho aparato. Ello debido a que el uso excesivo de este aparato puede ocasionar dolor de cabeza, artritis, déficit de atención, trastornos de sueño y hasta problemas de visión (ya que por ser un espacio reducido de $6 \mathrm{x} 3 \mathrm{~cm}$ con 35 botones aproximadamente, se requiere mayor concentración de la vista). Además, un $77 \%$ de los jóvenes utiliza con mayor frecuencia el Blackberry Messenger (UNIVERSIA, 2011). 
Por otro lado, se ha encontrado que muchos estudiantes se sienten más confiados al expresar sus sentimientos a través de este medio, que hacerlo cara a cara; y que mientras más tiempo pasen conectados quizá esto afecte ciertamente su forma de socializar y comunicarse en persona. Sin embargo, hoy en día los jóvenes usuarios de dicho aparato consideran de suma importancia contar con éste, ya que el solo hecho de tenerlo les brinda un mayor "status" frente a los demás y por ende, mayor popularidad al estar conectado con muchos amigos a la vez.

Existe peligro y a la vez fascinación por este universo virtual, el cual se suele conocer como el refugio de los tímidos, de los solitarios y hasta de los deprimidos a veces; ya que permite que estos se expresen libremente al tener una pantalla delante de sí y puedan huir o escapar sin tener que dar explicaciones sobre nada a nadie.

El uso inmoderado de internet se debe a diferentes razones. Por ejemplo, unos lo utilizan por la excitación que ocasiona y la adquisición de un nuevo sentido de identidad; otros lo utilizan para reducir las tensiones internas que puedan tener; otros lo utilizan para tener una compañía o simplemente sentirse acompañados; en general, como se puede notar estas serían personas que suelen sentirse solas.

El problema, vendría a ser cuando el uso del Smartphone se empieza a convertir en abuso, ya que este puede llevar a una dependencia o peor aún, a una adicción. En este sentido, existen dependencias relacionadas con la tecnología, los celulares con internet, las redes sociales, entre otras. Ciertas costumbres, distracciones o placeres, cuando se repiten más que nada por una necesidad que por una elección, podrían ser enfermedades reales. Estas conductas destruyen a estos usuarios, no solo a ellos, sino también a todos aquellos que los rodean (Lejoyeux y Adés, 2003).

Hoy en día existe cierto nivel de dependencia de los Smartphones; lo cual, se puede ver en los jóvenes actualmente que ya no memorizan números telefónicos de nadie, puesto que todos están almacenados en sus aparatos inteligentes; por ende, si se les pierde o se les malogra o simplemente no lo tienen un día, significa que están aislados del mundo todo un día. Asimismo, en el caso de que una persona sea adicta, puede perder el sentido del tiempo real y de este modo afectar sus relaciones interpersonales; así mismo, puede provocar trastornos de sueño, de alimentación, ansiedad, etc. 
Por otro lado, en general para los estudiantes, el entrar al mundo virtual, les genera más confianza para expresar sus emociones con mayor libertad que frente a frente y que además, utilizan este medio para ganar popularidad, por lo que muchas veces se producen competencias debido a este hecho (UNIVERSIA, 2011).

Este problema podría comenzar al momento en que se creó el primer celular con servicio de internet. Al crearse los celulares con internet, lo que se pretendía a grandes rasgos era minimizar el tiempo de espera ante el hecho de tener que llegar físicamente a algún lugar en el que haya una computadora para poder revisar los correos, buscar información en internet sobre lo que se necesite, estar en contacto con las relaciones sociales cercanas en todo momento, entre otros.

Esto se puede observar en los estudiantes universitarios, ya que cada día que pasa ellos desean obtener la información en el momento en que la necesitan y les resulta molesto tener que esperar unas horas o inclusive minutos para obtener aquello que buscan. La frase: "Lo necesito para ayer" es muy común hoy en día, ya que la población de estudiantes universitarios y jóvenes trabajadores se caracterizan por esta necesidad de rapidez en todos los procesos y tareas que realizan, en los trabajos para la universidad, en recibir las notas de exámenes que realizaron, etc.

Sin embargo, al minimizar el tiempo de espera mediante estos dispositivos, se corre el riesgo de perder la independencia y el tiempo de relajación fuera de los momentos en que hay que estudiar o ir a clases, ya que al ser un servicio que muchos adquieren, si bien podría servirles para estar en constante comunicación con sus pares y relaciones sociales, podrían continuar enviando y recibiendo mensajes de la universidad una vez terminado el día o semana de clases, otras personas dependen constantemente de la información que encuentren en internet sobre qué hacer o a dónde ir los fines de semana.

En realidad, los temas aquí mencionados se convierten en un problema, cuando dichos aparatos no se utilizan de manera moderada o controlada; lo cual, sí vendría a ser útil, tanto para los estudiantes como para las personas que trabajan. Grimaldos (2012), menciona que los Smartphones fueron diseñados para que el usuario tenga accesibilidad a conectarse en redes y de este modo facilitarle su vida en el día a día, pero últimamente, se ha visto que existe una gran dependencia en diversas personas al usar este dispositivo, por lo que se ha comprobado que muchas personas se 
consideran "adictas al Smartphone". Refiere que cuatro de cada diez adultos y adolescentes admiten que lo primero que ven al despertarse es su teléfono, por ello es que se cree que los usuarios se están volviendo dependientes de estos dispositivos, dejando de lado diversas actividades cotidianas.

De este modo, se puede ver que los celulares con internet pueden ser muy útiles si se utilizan de manera controlada. Sin embargo, si la utilización del Smartphone es de manera prolongada y sin pausas, podría estar afectando, tanto en la capacidad de socializar como en ciertas habilidades físicas. Dentro de los usuarios, existen jóvenes estudiantes, para los que la consecuencia de un uso descontrolado afectaría en cierto modo su rendimiento académico, la concentración para el estudio, la atención en las clases, etc. Sobre ello, no se han encontrado recientes investigaciones, específicamente sobre el uso del Smartphone y el rendimiento académico.

Todo ello, lleva a las siguientes preguntas: ¿Qué consecuencias podría tener el uso excesivo de este dispositivo en el rendimiento académico universitario?, ¿Cómo influye el Smartphone en el rendimiento académico de los estudiantes universitarios?, ¿Por qué las personas sienten la necesidad de utilizar constantemente su celular?

\subsection{Justificación y relevancia}

Este proyecto nació a partir de observaciones cotidianas hacia distintas personas que utilizan su celular con el servicio de internet en todo momento; esto es, en diversas situaciones como: cenas, reuniones, fiestas, salón de clases, lugares de trabajo, grupos de estudio, entre otros.

A partir de estas observaciones, se empezó a poner mayor atención a todas las personas que tienen los celulares con internet y a su comportamiento a partir del uso de éste en una u otra situación. De este modo, llama la atención ver a un grupo de personas sentadas en la mesa de un restaurante sin decir una sola palabra más que utilizar sus celulares con internet.

Se ha encontrado en los usuarios de los Smartphones comportamientos que se podrían considerar "problemáticos". Ello, debido a que lo utilizan para evitar contacto con otras personas o simplemente se pierden en este aparato e ignoran que hay gente 
alrededor de ellos. Por otro lado, la queja más común últimamente es el hecho de no poder desconectar la mente para ir a dormir (El Observador, 2011).

Del mismo modo, llama la atención ver parejas que van a comer juntas y ambos están digitando en sus celulares, ver jóvenes que van a reuniones y mientras unos cuantos hablan otros están digitando en su celular con internet, ver parejas bailando en una discoteca y ambos o uno de ellos digitando en su celular durante la pieza musical.

Otro acontecimiento que denota dependencia por parte de los usuarios hacia sus Smartphones, se da en una clase universitaria cuando un profesor, luego de advertirles a sus alumnos reiteradas veces que guarden el celular en sus mochilas durante la clase, al ver que no cumplían con dicha instrucción decidió hacer una caja en la que los alumnos, al entrar al salón de clases, guardarían sus celulares en silencio o apagados dentro de ésta. Acto seguido, al comenzar la clase y en el transcurso de ésta, el profesor se dio cuenta de que la gran mayoría de los alumnos observaba la caja constantemente, y una vez finalizada la clase, los alumnos se apresuraban a la caja, sacaban su celular inmediatamente y comenzaban a salir del salón mientras lo observaban y digitaban apresuradamente en éste, sin ver por dónde caminaban.

Este último hecho, brinda información importante, ya que llama mucho la atención que los jóvenes estudiantes no puedan concentrarse en la clase que se dicta, debido a que no presentan la capacidad de autorregularse para no mirar el celular (o la caja en este caso) durante la clase.

Según Vera (2012), los Smartphones son una gran salida de la realidad, ya que se han vuelto parte esencial de la vida de las personas de hoy en día, debido a todas las funciones que permiten a los usuarios utilizar, "obligándolos" a no apartarse de estos. Por ende, se genera una alta intranquilidad al momento de no tener el Smartphone con uno.

También comenta, que los Smartphones han tenido gran impacto en la sociedad, sobre todo entre los 13 y 35 años, al punto de crear la necesidad de revisarlo cada cierto tiempo para tener una vida social activa en todo momento. Se comenta también, que la misma sociedad es la que genera el estigma de que: "si no estás conectado no eres nadie", llegando a ser así, el Smartphone una extensión del cuerpo.

Finalmente, menciona también, ciertos aspectos positivos, como son: el uso que se le da para cuestiones netamente de trabajo (correos, modificación de documentos, entre 
otros), y aspectos negativos sobre el uso del Smartphone, como son: llamativos para los ladrones, problemas en los ojos al realizar esfuerzos de lectura ante pantallas pequeñas, tendencia a disminuir interacciones personales, la postura física al momento de leer el Smartphone puede ocasionar problemas de espalda o cuello o dolores musculares, también están los problemas de sueño, entre otros.

Por todo lo antes mencionado existe un gran interés en el tema; ya que resulta ciertamente sorprendente que las personas, se puedan aferrar tanto a una cosa material, generando una especie de relación con ésta; de modo que, pase de ser un simple celular con servicio de internet a ser "el compañero fiel que va con uno a todas partes".

Asimismo, esta investigación permitirá brindar aportes tanto interesantes como innovadores al ámbito psicológico, desde una perspectiva cualitativa. Ello, debido a que al tratarse de un estudio exploratorio y descriptivo conlleva al descubrimiento de nuevos conceptos y percepciones que puedan servir de apoyo para encontrar, en este caso, los posibles aspectos que implique el uso del Smartphone en las diferentes personas y a la vez, de manera práctica, crear conciencia en los jóvenes de hoy en día para que puedan controlar su tiempo de una mejor manera y aquello en lo que lo emplean. 


\section{CAPÍTULO II : MARCO TEÓRICO}

\subsection{Internet}

\subsubsection{Definición de internet}

El internet es definido básicamente del mismo modo por diversas fuentes. Sin embargo, para la presente investigación se hará referencia a los aspectos y características básicas del internet, para que mantenga relación con el tema a tratar. En este sentido, el internet se define como una red de redes que permite la interconexión descentralizada de computadoras a través de un conjunto de protocolos denominado TCP/IP (son protocolos de red en los que se basa internet y permiten la transmisión de datos entre computadoras) (Definición.DE, 2015).

Ello se originó en 1969, cuando una agencia de Departamento de Defensa de Estados Unidos comenzó a buscar alternativas ante una eventual guerra atómica que pudiera intercomunicar a las personas. Luego de tres años se realizó la primera demostración pública del sistema creado.

Según lo antes mencionado, es importante mencionar la diferencia entre dos términos, Internet y la World Wide Web. La WWW es un sistema de información desarrollado en 1989, este servicio permite el acceso a información que se encuentra enlazada mediante el protocolo HTTP (Hiper Text Transfer Protocol).

El desarrollo de internet ha superado ampliamente cualquier previsión y constituyó una verdadera revolución en la sociedad moderna. Lo que ocurrió aquí fue que el sistema se transformó en un pilar de las comunicaciones, el entretenimiento y el comercio en todos los rincones del planeta (Definición.DE, 2015).

\subsubsection{Uso y abuso del Internet}

La expansión de las tecnologías de la comunicación ha avanzado a gran velocidad. La forma en que las personas interactúan con los demás y el cómo se ven a 
sí mismas, está ciertamente influenciada e impulsada por el mundo on-line. La propensión de la memoria selectiva facilita el hecho de adoptar nuevos hábitos de manera rápida y de olvidar la manera de realizar las cosas antes de esta nueva adopción.

Antes del siglo veintiuno el número de personas conectadas a internet era de aproximadamente 350 millones y durante la primera década del siglo veintiuno este número aumentó hasta llegar a los 2000 millones de usuarios aproximadamente. Sin embargo, en la actualidad existen por lo menos 240 millones de usuarios de la red. Durante la primera década del siglo veintiuno, el número de usuarios del teléfono con servicio de internet aumentó desde los 750 millones hasta 5000 millones. Sin embargo, hoy en día existen más de 6000 millones de usuarios de teléfonos celulares que cuentan con el servicio de internet (Schmidt y Cohen, 2014).

Según Ron, Álvarez y Núñez (2013), las redes digitales y las nuevas aplicaciones suelen ser útiles en dos grandes áreas. La primera se refiere a lo profesional y la segunda al ocio. En realidad, primero se comenzó utilizando el correo electrónico en la década de los 90, luego se aprendió a navegar por páginas web, luego se fueron creando las comunidades virtuales, a continuación, se empezó a compartir en las redes sociales, luego se empezaron a utilizar los servicios financieros y las compras a través de las diversas páginas web, etc.

Mencionan también, que con las tablets y las aplicaciones el uso de la tecnología para el ocio está creciendo de una manera muy rápida no sólo para los jóvenes y adolescentes, sino también para los adultos. En realidad la visión de ocio para los jóvenes de hoy en día es totalmente diferente a la visión de ocio por parte de los adultos, ya que para estos últimos significaba ver televisión con la familia; mientras que para los jóvenes el ocio es ver series en su dispositivo digital.

Schmidt y Cohen (2014), plantean que todas aquellas personas que utilizan el internet suelen vivir en dos "mundos" paralelos; estos son, el "mundo virtual" y el "mundo físico". En el primer mundo, se experimenta cierto nivel de conectividad de forma rápida y a través de diversos medios y dispositivos.

En cambio, en el segundo mundo, se debe lidiar con la geografía, la mala suerte y los lados, tanto bueno como malo, que pueden encontrarse en la naturaleza de todo ser humano hoy en día. Cada vez que aparecen nuevas tecnologías se fortalecen las 
sucesivas generaciones. Por ende, actualmente el hecho de tener el acceso a información y a los nuevos canales de comunicación es sinónimo de tener nuevas oportunidades de participar, de mantener el poder dirigir el curso de la propia vida.

Lejoyeux y Adés (2003), comentan mucho sobre el peligro y a la vez la fascinación de este universo virtual, el cual es considerado en cierto modo como el refugio de los tímidos, de los solitarios y hasta de los deprimidos a veces; ya que permite que estos se expresen libremente al tener una pantalla delante de sí y puedan huir o escapar sin tener que dar explicaciones de absolutamente nada a nadie. El uso inmoderado de internet se debe a diferentes razones. Por ejemplo, unos lo utilizan por la excitación que ocasiona y la adquisición de un nuevo sentido de identidad; otros lo utilizan para reducir o minimizar las tensiones internas que puedan tener; otros lo utilizan para tener una compañía o simplemente sentirse acompañados; en general, estas serían personas que suelen sentirse solas.

Refieren además, que el problema se da cuando el uso del celular se empieza a convertir en abuso, es decir el tiempo de utilización se vuelve cada vez mayor o empieza a interferir de alguna manera en su día a día, ya que este puede llevar a una dependencia o inclusive adicción. En este sentido, los autores afirman que existen dependencias relacionadas con la tecnología, los celulares con internet, las redes sociales, entre otras tendencias virtuales. En muchos casos; ciertas costumbres, distracciones o placeres, cuando se repiten más que nada por una especie de "obligación interna" y no por propio gusto; es decir, más por una necesidad que por elección, podrían constituir enfermedades reales. Estas conductas en aquellas personas que las desarrollan, lo que ocasionan es destruirlas, no solo a los usuarios, sino también a todos aquellos que los rodean.

Asimismo, comentan que durante los últimos años, las publicaciones médicas y las no tan rigurosamente científicas se han ido multiplicando, debido a que el uso del internet no para de crecer, alentado por los juegos con dinero, compras, subastas, pornografía, juegos de bolsa de valores, y así, entre otros. Por ende, el tiempo de conexión a internet aumenta cada vez modulando (y en muchos casos perjudicando) las actividades diarias que solían tener muchas personas hasta entonces. Estos hallazgos ocasionaron que se le tome mayor importancia al tema, generando que se 
elaboren nuevas técnicas para medir las mencionadas relaciones dependientes. En realidad, lo que podría conllevar a una dependencia es que la utilidad de dicha herramienta pase a ser una necesidad para el usuario y que los efectos negativos estén estrechamente relacionados con su uso. Es así, que algunos desarrollan una necesidad de tener conexión permanente con otras personas, lo cual es dable a través del celular y va mucho más allá de la necesidad o comodidad de estar en contacto con los demás.

Marc Pratarelli, psicólogo americano elaboró un cuestionario para catalogar a las personas que utilizan internet en demasía, impidiéndoles cumplir sus funciones y o actividades diarias de manera fluida. (Como se citó en Lejoyeux y Adés, 2003). De aquí, se extienden los "perfiles tipo" de los usuarios de internet, los cuales son:

Los razonables quienes utilizan el internet con moderación, ya que la computadora es necesaria, pero las nuevas tecnologías no les fascinan. Juzgan el rápido desarrollo de internet como inútil o peligroso, ya que no son dependientes y prefieren las relaciones directas.

Los adictos de la web son aquellos que suelen pegarse al mundo del internet y aislarse del mundo real. Pueden perder amigos, descuidar a su familia, perder el apetito o incluso el sueño. La primera conducta de este grupo de personas suele ser el hecho de mirar su celular o computadora en cuanto se levantan, luego de haber dormido toda la noche.

Los enganchados al cibersexo son todos aquellos para los que el acceso a internet es básicamente para ingresar a webs eróticas o pornografía. El uso de internet por este grupo reúne dos tipos de adicción: el uso compulsivo de internet y la adicción sexual.

Asimismo, Lejoyeux y Adés (2003), definen la adicción como un uso mal adaptado de internet que lleva a una angustia o a una minusvalía significativa, que se manifiesta por tres (como mínimo) de los criterios siguientes que se pueden dar en cualquier momento durante un periodo de al menos un año: 
1- Tolerancia, definida por uno de los dos síntomas siguientes:

a) Necesidad de pasar un tiempo cada vez más importante en internet para obtener satisfacción.

b) Neta disminución que se siente cuando el tiempo pasado en internet se mantiene constante.

2- Abstinencia, manifestada por uno de los síntomas siguientes:

a) Síndrome de abstinencia característico.

a.a) Cese o reducción del uso de internet de manera clara y prolongada.

a.b) Dos o más de los síntomas siguientes que sobrevienen a partir de algunos días hasta un mes después del cese o la reducción:

- agitación psicomotriz;

- ansiedad;

- pensamientos obsesivos concernientes a internet;

- sueños o ensoñaciones a propósito de internet;

- movimientos voluntarios o involuntarios de los dedos tecleando.

a.c) Los síntomas del criterio a.b comportan un sufrimiento o molestia en la vida social, profesional o en cualquier otra actividad importante.

b) Recurso al uso de internet (o cualquier otro servicio on-line) para evitar o parar los síntomas de abstinencia.

3- $\quad$ El uso de internet es a menudo más largo y más prolongado de lo previsto.

4- Deseo persistente y esfuerzos infructuosos para controlar o parar el uso de internet.

5- Tiempo importante pasado en actividades ligadas al uso de internet (por ejemplo: compra de obras

6- especializadas, búsqueda de vendedores de portales de acceso, organización de listas de webs cargadas en el ordenador, etc).

7- Reducción o cese de actividades sociales, profesionales o de ocio relacionadas con internet.

8- Continuación del uso a pesar del conocimiento de problemas físicos, sociales, profesionales, psicológicos persistentes o recurrentes, provocados o agravados por el uso de internet (trastornos de sueño, dificultados conyugales, retraso en las citas, 
abandono de las tareas profesionales, sentimientos de abandono por parte de los allegados).

Por otro lado, mencionan que de 18000 usuarios, que fueron evaluados en Estados Unidos por la Asociación Americana de Psicología, un 5\% de ellos son realmente "drogados de la web". Entre aquellos que calificaron como "dependientes" un $83 \%$ siente la necesidad imperiosa de conectarse, un $69 \%$ ha intentado (lamentablemente sin éxito) reducir su tiempo de conexión en el internet y un $80 \%$ de aquellos calificados como "adictos a internet" ha presentado signos de abstinencia; como son: irritabilidad, melancolía, trastornos del sueño; cuando intentó disminuir su uso. A partir de la identificación de la denominada "adicción a internet", Goldberg creó una página web de ayuda llamada "Internet Addiction Support Group" ("Grupo de soporte para adictos a internet"), dentro de la que se llevan a cabo discusiones e intercambios con los participantes de dicho foro. Adicionalmente, este foro permite realizar un autodiagnóstico a través de ciertos criterios y brinda consejos sobre la utilización de internet. Del mismo modo, hoy por hoy existen diversos foros y páginas webs que brindan consultas y tratamientos on-line.

\subsubsection{Consecuencias del Uso y Abuso del Internet}

Las consecuencias del uso del internet actualmente se dan en la medida en que el espacio que antes era utilizado para la experiencia individual, ahora es un espacio en el que hay imágenes, diversos referentes, versiones y visiones. La instantaneidad, el volumen y desorden de la información acortan la relación con los sucesos, los lugares

y realidades, ya que el contacto con las realidades de otros lugares es cada vez más percibido como algo natural, como algo esperable y deja de ser sorprendente o surreal (Quiroz, 2001).

En cuanto a las consecuencias del uso y abuso del internet, Turkle (2011), estudió las interacciones con la tecnología y efectos que tiene en la vida de cada persona; y por tanto, propone que el uso del internet conduce a una menor interacción 
social, ya que por estar conectados a la web o utilizando algún aparato virtual se deja de socializar con otras personas. Su estudio se basa en la preocupación por el desarrollo y aprendizaje social de niños y adolescentes. Indica que los aparatos tecnológicos han ido reemplazando otro tipo de relaciones. Hace algún tiempo se dio en los niños por medio de juguetes, como las "mascotas virtuales" o los "ferbies". Debido a estas mascotas virtuales, se cree que tiene muchos beneficios; como que no genera alergias, no morirá, ni dejará sola a la persona. De esta forma, el robot se convierte en algo preferible a la interacción real. Este ofrece control total sin sorpresas, una relación hecha a la medida donde uno puede tener las cosas exactamente como las quiere. Es así, que las personas suelen buscar satisfacer cierta necesidad de apego en los robots, ya que éstos les brindan todo aquello que desean y es controlable. Sin embargo, con estos la relación afectiva es unilateral; puesto que, estos no tienen expectativas de uno, es por eso que se vuelven preferibles. De esta manera, las personas trasladan este tipo de relación a sus amistades; esperando así, menos de ellos.

\subsubsection{Definición de Smartphones}

Un Smartphone es definido como un teléfono inteligente, según la lengua inglesa. Es un teléfono celular (móvil) que ofrece prestaciones similares a las que brinda una computadora y se destaca por su conectividad. Usualmente se ubica al Smartphone a mitad de camino entre un teléfono celular convencional y una computadora portátil. En este sentido, el Smartphone cuenta con todas las funciones básicas de un celular (permite realizar llamadas telefónicas, enviar mensajes de texto, etc) y le agrega características avanzadas (conexión a internet, pantalla táctil, capacidad multimedia, etc).

Actualmente existen diversos tipos de Smartphones, algunos con mayor cantidad de funciones que otros. Con un Smartphone es posible que una persona pueda conectarse a la web a través de una red $3 \mathrm{G}$ o $\mathrm{WiFi}$, consultar una ubicación mediante GPS, reproducir archivos MP3 o de vídeo, sacar fotografías y grabar videos, utilizar 
juegos, gestionar una agenda y/o hasta visualizar documentos de trabajo creados en PDF u otros formatos.

Entre los sistemas operativos (conjunto de programas informáticos que permite la administración eficaz de los recursos de una computadora, ya que gestionan el hardware del dispositivo móvil desde los niveles más básicos y permiten la interacción con el usuario) que se emplean en los Smartphones están: iOS, Android, BlackBerry OS, Symbian OS y Windows Phone. Entre los fabricantes de esta clase de dispositivos están: Samsung, Sony, Nokia, LG, Motorola, Alcatel, BlackBerry y Apple. Un ejemplo de Smartphone es el iPhone que fabrica Apple. Permite escuchar música, tomar fotografías, conectarse a internet vía WiFi, recibir y enviar mensajes de voz y de texto, entre otras funciones (Definición.DE, 2015).

\subsubsection{Uso y Abuso de los Smartphones}

Cruz (2012), comenta que la venta de celulares a nivel mundial aumentó en el año 2011 en un 1\%, mientras que la venta de Smartphones aumentó en un 42,1\%. Ello se debe a los beneficios que dichos aparatos presentan; como estar conectados permanentemente con los demás, alta flexibilidad para trabajar en cualquier lugar (desde el Smartphone) y las alternativas diversas de entretenimiento.

Asimismo, Cruz (2012), identificó los tipos de usuarios de Smartphones que existen hoy en día; estos son: los usuarios de Gama Alta (que son los clientes más exigentes del mercado, siempre pendientes de las últimas innovaciones, ya que necesitan un celular que tenga las funciones más avanzadas), los de Gama Media (aquellos que buscan un celular que cuente con características y funciones avanzadas, pero a un precio más accesible) y los usuarios de Gama Baja (aquellos que de igual modo, quieren vivir toda la experiencia de que brinda un Smartphone, pero a la vez quieren pagar un bajo precio por él).

Por otro lado, uno de los factores que tiene mayor influencia en la decisión de compra de un Smartphone es el sistema operativo con el que cuenta, ya que determina la rapidez y fiabilidad de todos los procesos. Durante los primeros años de venta de los 
Smartphones, los usuarios se enfocaban más en temas como: el tamaño de la pantalla, la velocidad del aparato, la cámara y la capacidad de memoria. Sin embargo, hoy en día esto ha cambiado, ya que los usuarios se están enfocando en otros temas, como: la eficiencia de la batería, el poder utilizar las nuevas aplicaciones, la permanente conexión a las redes sociales como: Facebook, Twitter, Whatsapp, Foursquare, Messenger, Shazam, Instagram, Angry Birds, entre otros.

En el Perú, durante el primer semestre del 2012, las ventas de Smartphones crecieron más del $120 \%$. Se encontró también que en el Perú, los usuarios se fijan mucho en la funcionalidad, las posibilidades de conexión del Smarthpone, en el cumplimiento de lo prometido tecnológicamente por parte de las marcas y buscan tener una calidad superior en cuanto al funcionamiento. Los Smartphones se han convertido en una herramienta imprescindible no solo para los ejecutivos, sino en general para todos los profesionales. El consumidor peruano está comprendiendo cada vez más el valor que le ofrece un plan pospago, ya que dicho plan cuenta con la conexión permanente a internet, correo electrónico, acceso a noticias, páginas web de su preferencia y el acceso a redes sociales en el momento que desee y en el lugar en el que se encuentre (Cruz, 2012).

Según Jiménez-Murcia y Farré Martí (2015), el trayecto del Smartphone, aparte de ser una novedad tecnológica, socialmente implica un cambio en la experiencia vital de cada uno. Asimismo, en el 2013 se vendieron más de 1000 millones de Smartphones en el mundo entero; esto es, 300 millones más que en el año 2012. A ello, se añade el uso de las aplicaciones, las cuales fueron utilizadas por 1.200 millones de personas hacia el final del año 2012; lo cual, se piensa que crecería un $30 \%$ cada año, pronosticando una cifra de 4400 millones de usuarios para el año 2017. Por tanto, el $85 \%$ de usuarios utiliza su Smartphone para conectarse a internet, ello se debe a diversos factores como: el bajo costo de los dispositivos y tarifas, la normalización del uso de este dispositivo dentro de la sociedad, entre otros. De este porcentaje mencionado, el 70.7\% se conecta diversas veces durante el día. Así mismo, el tiempo de uso diario que le da un $6.9 \%$ de los usuarios es de más de 4 horas, $8.1 \%$ de usuarios utiliza este dispositivo entre dos y cuatro horas y un $13.7 \%$ lo utiliza entre una y dos horas. 
Según Castro (2012), el celular es una de las tecnologías que ha llegado a tener la mayor y más rápida inserción en la sociedad como plataforma de información y acceso a contenidos. Esto se debe a que en sus inicios los celulares fueron elaborados para comunicarse a través de un medio auditivo. Luego, se fueron adhiriendo nuevas aplicaciones; así como, servicios por parte de las operadoras; logrando la existencia de los Smartphones en la actualidad, los cuales permiten: enviar mensajes, tomar fotos, escuchar música, navegar por internet, enviar mails, usar GPS, descargar juegos, organizar actividades del día, chequear cuentas bancarias, escribir en blogs, entre otras funciones.

Además, refiere que los Smartphones permiten además, percibir a otros cerca, pese a que estén lejos físicamente. Así también, permiten los negocios en red, la oficina móvil, la descentralización de la producción, la gestión en el mundo empresarial y la conexión directa de los usuarios y servicios públicos. Esto conlleva además, a que el uso de líneas de telefonía fija haya disminuido en gran medida.

Indica que existen hoy en día 4 categorías de teléfonos celulares. Primero están los Teléfonos Básicos, los cuales permiten la comunicación de voz, mensajes de texto, cámara de fotos de baja resolución y escasa capacidad para reproducir archivos de audio. Luego están los Feature Phones, los cuales, además de las funciones mencionadas en la categoría anterior, poseen la capacidad de reproducir archivos MP3, cámara de alta resolución y diversos ajustes para mejorar las capturas. Seguidamente está la categoría llamada Teléfonos Sociales, los cuales, sin ser Smartphones, contienen lo mencionado en la categoría anterior, adicionando que son equipos con múltiples funciones de mensajería, teclado QWERTY, pantalla táctil, uso del correo, mensajería instantánea (Messenger, Yahoo, Whatsapp) y diversas redes sociales (Facebook y twitter). Finalmente, los Smartphones, que, además de lo antes mencionado, contienen sistemas operativos propios y la posibilidad de cargar nuevas aplicaciones, pudiendo realizar mayor cantidad de tareas que cualquiera de las categorías antes mencionadas. Se encontró además, que en los años 2009, 2010 y 2011 los celulares más vendidos fueron los Teléfonos Sociales (Social Phones) y los Smartphones. Los primeros registraron un aumento de 600\% y los Smartphones crecieron en un 225\%. 
Schmidt y Cohen (2014), indican que los Smartphones se utilizan en la actualidad para diversas cosas. Se utilizan para búsqueda de información, para controlar envíos de medicamentos (y verificar su autenticidad), para compartir información sanitaria básica (no disponible localmente), enviar recordatorios sobre medicación y citas a los pacientes, entre otros.

Refieren que estos dispositivos con servicio de internet, brindan a las personas un nuevo nivel en cuanto a su salud personal. Esto es, se puede utilizar dicho aparato para acceder a diagnósticos básicos sobre enfermedades, como despertador en las mañanas, como block de notas, recordatorios de eventos o actividades, GPS, cámaras y grabaciones de audios (por ejemplo: la fotografía de una lesión o grabación de una tos y enviarlo a un médico), ingresando a páginas web diversas (como Twitter, Facebook, Web de noticias, etc) a través de las cuales se brinda o se obtiene información. Asimismo, el uso del celular con servicio de internet permite que exista mayor cantidad de gente conectada a las redes y que por ello sepan lo que ocurre en diversos países. Es así, que dicha conectividad hace amplía el compromiso con sucesos externos a uno. El hecho de establecer las comunicaciones podría permitir la construcción de la infraestructura física, económica y política al mismo tiempo.

El celular con servicio de internet es utilizado en gran proporción hoy en día básicamente para consultar dónde se encuentra uno y con quién, se consulta el celular decenas de veces al día mensajes sin contenido. Los "enganchados al celular" parecen estar más al asecho de las relaciones telefónicas que de las relaciones humanas presentes físicamente. Es por ello que se puede ver hoy en día, gran cantidad de personas conversando por teléfono o chat al lado de amigos que hacen lo mismo mientras manejan el carro, aún siendo conscientes del peligro que ello implica (Lejoyeux y Adés, 2003).

El problema del uso del Smartphone podría aparecer cuando éste se convierte en abuso, debido a que puede generar una dependencia o hasta una adicción. Hoy en día es difícil imaginar la vida sin celulares con servicio de internet, ya que en esta época de "Smartphones" sus usuarios tienen la seguridad de que no olvidarán nada porque en estos aparatos tienen acceso a todo un mundo de ideas y adicionalmente, siempre se 
encuentra algo con lo que se puede ocupar la atención, pese a que puede hacerse de manera útil, puede llegar a resultar lo contrario también (Schmidt y Cohen, 2014).

El Smartphone, según Jiménez-Murcia y Farré Marti (2015), empieza a ser una amenaza en la medida en que interfiera con las obligaciones o actividades de tiempo libre de cada uno, es decir que se pierde interés en estas. Ello, si se empieza a dar en la adolescencia (que es considerada una etapa sensible) puede llevar a conflictos con los padres y negación de la existencia de algún problema por parte de los adolescentes; llevando así, a la generación de conflictos en diversas áreas, como: personal, académica, social, etc. Esto se consideraría una adicción, en el caso de aparecer el problema de manera prolongada durante el tiempo.

Según Jiménez-Murcia y Farré Marti (2015), en esta etapa de adolescencia se dan los siguientes comportamientos y capacidades: rápido aprendizaje, sensación más extrema de placer/recompensa/frustración, mayor capacidad de motivación por lo que les atrae y mayor apatía por aquello que no, menor capacidad de juicio y consideración de consecuencias sobre sus actos y menor organización. Además, muestran mayor interés por actividades como: relaciones sociales, sexualidad, novedades, actividades de bajo esfuerzo y alta excitación, actividad física y aquellas que causan sensaciones fuertes. Por lo anteriormente mencionado, se afirma que los niños, adolescentes y jóvenes sienten especial atracción hacia la tecnología; la cual, les ofrece: necesidad de autonomía, búsqueda de la propia identidad, importancia de los amigos, necesidad de ocio, riesgo y experimentación, y establecimiento de primeras relaciones amorosas. Todo ello, lleva a los autores a plantearse los inconvenientes de esta utilización excesiva del aparato, como son: la pérdida de privacidad e intimidad familiar, cambios en las formas de interacción y relaciones sociales. Por lo que se encontraron diversos factores que ocasionan inconvenientes en cuanto al uso del Smartphone: el uso inadecuado y excesivo (es fácil de usar y existe presión social para utilizarlo), el abandono de actividades de ocio, podría haber interferencia con otras áreas básicas básicas del niño o adolescente, podría desencadenar problemas familiares (discusiones por su uso, por ejemplo), problemas de privacidad (como mostrar su localización o que aparezcan datos sobre el lugar donde vive el usuario o donde trabaja, etc), contacto con 
desconocidos y recepción de mensajes con contenidos inadecuados, violencia verbal y amenazas, envío de fotografías íntimas y en general el uso problemático y adicción.

Respecto al uso del Smartphone, un $37 \%$ de adultos y un $60 \%$ de adolescentes refieren tener una adicción a su aparato inteligente, el 30\% de los usuarios de dicho aparato confiesa utilizar los Smartphones para tener temas de conversación en las horas de trabajo. Además, se ha comprobado que la mayoría de los usuarios de los teléfonos inteligentes los mantienen las 24 horas prendidos y que responden las llamadas incluso si éstas se dan en las noches. Finalmente, el $10 \%$ de estos usuarios refiere haber terminado sus relaciones románticas por medio de estos aparatos (RT, 2011).

La dependencia de las telecomunicaciones refleja la importancia de la tecnología en diversas sociedades, incluso en las más pobres. Cuando se habla de restablecer la red, se habla específicamente de los servicios de voz y texto, no de la conectividad a internet. Esto está cambiando en la actualidad, ya que los usuarios se están basando cada vez más en los servicios de datos y menos en las comunicaciones de voz (Schmidt y Cohen, 2014).

Existe una diferencia entre el uso problemático del dispositivo y la adicción, según Jiménez-Murcia y Farré Martí (2015). En cuanto al primero, refieren que se presenta alguno de los siguientes cuatro criterios durante un período de tiempo prolongado: la utilización del Smartphone ocasiona el incumplimiento de las obligaciones (sean domésticas, laborales, escolares, etc), utilizan el dispositivo en situaciones que podrían ser peligrosas tanto para los usuarios como para los demás, el usuario tiene problemas ocasionados por la utilización del dispositivo cuando se supone está prohibido utilizarlo (como manejar) y la utilización del Smartphone ocasiona problemas con el entorno del usuario (tales como: amigos, familiares, pareja, etc).

Afirman también, que además de lo antes mencionado, los usuarios presentan síntomas que muestran que necesitan las tecnologías de manera des adaptativa y se generan serios problemas en los aspectos familiares, personales, sociales, académicos y/o laborales. Mencionan algunos criterios representativos de la adicción; como son: la tolerancia (se presenta de modo que el usuario necesita utilizar con mayor frecuencia el Smartphone porque lo utilizado inicialmente no es suficiente), abstinencia (el usuario presenta malestar cuando se le interrumpe la utilización del dispositivo que puede 
manifestarse como enfado, ansiedad, agresividad, etc), la utilización del Smartphone es mayor de lo planificado, existe una ausencia de control por parte del usuario (ya que no puede dejar de utilizarlo), el tiempo de utilización es excesivo al punto de interferir con actividades cotidianas, el usuario deja de hacer diversas actividades por la utilización del Smartphone, finalmente se continúa utilizando el dispositivo a pesar de saber que es perjudicial para el usuario.

Refieren que la adicción al Smartphone se entiende como una adicción comportamental, ya que aquello que lo convertiría en "adictivo" es la función de comunicación interpersonal instantánea y permanente. Ello se refiere a que las comunicaciones son inmediatas. Este sentido de inmediatez es considerado uno de los principales agentes adictivos, tanto en drogas como en adicción al juego, por ejemplo.

Ron et al (2013), comentan que hoy en día existe un afán de curiosidad muy grande, en el que las personas muestran una actitud constante de saber y ver lo que hacen los demás. Ello está convirtiendo a las redes digitales en una especie de "gran hermano" digital, en el que todos están conectados observando la vida de otros y pueden pasar mucho tiempo haciéndolo (desde donde se encuentren). Muchos usuarios de los dispositivos con internet, al darse cuenta de que no tienen su celular experimentan mucha angustia y ansiedad. Es por ello, que es importante reflexionar sobre el tiempo de conexión que mantienen hoy en día los usuarios con sus Smartphones o celulares con servicio de internet, ya que es importante dejar la tecnología un momento y poder relacionarse con las personas que los rodean físicamente en ese momento.

Lo mencionado en el párrafo anterior, guarda relación con lo que hoy en día se conoce como la nomofobia o el miedo irracional a salir a la calle sin el teléfono móvil, ya que se piensa que ésta puede crear inestabilidad, agresividad o dificultades de concentración. Se dice que el 53\% de los usuarios son afectados por la nomofobia. Sin embargo, en una comparación de géneros, se encontró que las mujeres experimentan menores niveles de ansiedad que los varones cuando tienen poca batería en el celular; esto es, el $48 \%$ de las mujeres experimenta dicha ansiedad, mientras que un $58 \%$ de los varones la experimenta (en ambos casos, los porcentajes se refieren a la población encuestada) (ABC.ES, 2011). 
El uso del Smartphone actualmente es para los jóvenes como una pareja; ya que lo ven como a su compañero fiel e inseparable que los entiende, les permite hacer las cosas que quieren, ofrece contenidos e información, les permite pasarla bien y reírse, etc (Ron et al 2013).

Estos dispositivos, según, se han convertido en un objeto muy personal, ya que estos van con los sujetos a todas partes, creando un lazo inquebrantable entre el teléfono y su dueño. Es por ello, que se reconoce que el Smartphone ha adquirido un lugar privilegiado para su usuario. Estos celulares enlazan las prácticas sociales en diversos lugares, ya que crean un sub-espacio de comunicación dentro de un espacio determinado, generando así, la sensación de estar en diferentes lugares a la vez (Castro, 2012).

Es importante reflexionar sobre cómo el mundo tecnológico está impactando a jóvenes y adolescentes en su día a día. Es decir, realmente disfrutan de una fiesta o concierto o es que solamente están pendientes de tomar fotos para colgarlas en sus redes sociales, pensar si realmente aquello que cuelguen en las redes les podría costar caro más adelante, evaluar hasta qué punto pueden compartir asuntos privados o íntimos en las redes, entre otros (Ron et al 2013).

\subsubsection{Consecuencias del Uso y Abuso de los Smartphones}

Schmidt y Cohen (2014), indican que la expansión de la conectividad y en particular a través de los celulares con servicio de internet, es el ejemplo más común y quizá más profundo de este cambio de poder. La incorporación digital es para algunos la primera experiencia de fortalecimiento de sus vidas; ya que les permite ser oídos, considerados y tomados en serio; mediante un dispositivo que se puede llevar tranquilamente en el bolsillo de un pantalón o de una camisa. Se puede ver que como consecuencia inicial, los celulares con servicio de internet están transformando la forma en que las personas de un mundo desarrollado acceden a este y utilizan la información. Además, la cantidad de personas que adquieren un Smartphone aumenta mes a mes y año a año. Tal es así, que hoy en día existen más de 650 millones de 
usuarios en África y aproximadamente 3000 millones en Asia, según indican los autores. La conectividad a internet, más allá de los Smartphones, aporta la capacidad de obtener y utilizar datos; los cuales son una herramienta muy eficiente, sobretodo en lugares en los que la necesidad de estadísticas sobre salud, educación o economía ha detenido el crecimiento y el desarrollo de una población. En realidad, es sorprendente cómo es que el avance tecnológico, el aumento de la conectividad y la interdependencia que se forma entre los países, hacen que el mundo parezca más pequeño. Ello podría cambiar la forma en que las empresas u organizaciones interactúan con socios, clientes o empleados de diversos lugares del mundo.

Por otro lado, Ron et al (2013), siguiendo con el establecimiento de relaciones, afirman que otra consecuencia del uso de los Smartphones es que muchos jóvenes y adolescentes de hoy en día coinciden en que la mejor forma de romper la brecha generacional entre sus padres y ellos mismos fue la aparición del Smartphone con todas sus aplicaciones, permitiendo a los jóvenes enseñarles a los de la generación anterior cómo utilizarlas, para qué servía cada aplicación, entre otras direcciones.

Así mismo, refieren que los jóvenes consideran que el ocio es la manera más accesible de romper la brecha entre su generación y la generación anterior a ellos. Ellos piensan que el ocio puede acercar a dos generaciones o más de una manera natural y que puede dar resultados muy satisfactorios; ya que hay mayor comunicación, se estrechan los lazos de amistad y afectivos, se comparten diversas experiencias, entre otras razones. Algo que el Smartphone y la tecnología ha ocasionado en los jóvenes de hoy en día es la capacidad de multitasking que tienen, ya que pueden realizar varias tareas a la vez. Ello se debe a que cada vez utilizan estos aparatos con mayor precocidad. Sin embargo, esta sobre-estimulación puede causarles dificultades en la inteligencia ejecutiva, ya que reaccionan con mucha rapidez pero luego no recuerdan nada; por lo tanto, dichas acciones solo quedan en la memoria de corto plazo y no entran a formar parte de la experiencia almacenada en la memoria de largo plazo.

Podrían existir consecuencias no necesariamente positivas sobre el uso de los Smartphones, ya que la mayor conectividad entre sociedades también podría proporcionar, a aquellos que practican la discriminación, formas nuevas de marginar a 
las minorías y a otras comunidades que les desagraden, lo cual estaría siendo facilitado por la tecnología. La intimidación on-line por parte de grupos extremistas es más fácil de perpetrar porque internet deshumaniza la interacción, dando así cierto grado de anonimato; ya que, se escriben cosas que no necesariamente se dirían cara a cara o que quizá hasta les avergüence decirlas por teléfono. Los Smartphones ayudan creando oportunidades en educación, asistencia sanitaria y seguridad, oportunidades comerciales, fuentes intelectuales, sociales y de entretenimiento para las diversas poblaciones. Por otro lado, el internet produce cierto anonimato que genera una especie de aislamiento protector que incentiva a continuar en el anonimato (Schmidt y Cohen, 2014).

En la actualidad, los jóvenes y adolescentes pueden estar en sus cuartos con el Smartphone o la computadora, desde donde gestionan su vida en clave digital; aislándose de las personas que tienen cerca físicamente en ese momento. Es importante analizar y reflexionar sobre si estos aparatos fueron creados para unir a las personas (sea en el entorno normal de su vida, en los centros de trabajo, lugares de enseñanza o en el hogar) o están siendo utilizados ocasionando justamente lo contrario; creando aislamiento y distanciamiento unos de otros (Ron et al 2013).

Según Castro (2012), la rápida expansión de los Smartphones ha generado cambios sociales y culturales, han modificado las formas de comunicación, de acceder a la información y las maneras en que los individuos se relacionan entre sí. El uso de estos aparatos ha modificado la forma de trabajar, aprender, colaborar, jugar, pasar el tiempo y hasta la forma de socializar que presentan hoy en día los usuarios.

También afirma que actualmente, se puede ver que la tecnología interactúa a diario y en diversos espacios con las personas, permitiéndoles mantenerse en contacto mutuo. Los Smartphones se han convertido en los compañeros fieles de los usuarios, más que en una herramienta, un fin en sí mismos, al extender tecnológicamente el sistema nervioso central de dichos usuarios. Se observan cambios en la vida cotidiana, en las maneras de trabajar, estudiar, consumir o vincularse en la percepción del tiempoespacio de los usuarios. Una característica esencial del Smartphone es su prolongada y permanente conectividad, ya que esta no depende del lugar sino de la persona. Es por ello, que se dice que es el complemento insustituible del usuario (quien es considerado 
como sujeto social). Asimismo, las actividades y tareas que antes estaban contenidas en espacios y tiempos de trabajo, se ven modificadas por el uso de Smartphones. Ello también conlleva a que se modifique el comportamiento público, se alteraron los conceptos de "espacio público" y "espacio privado", relaciones humanas, costumbres, forma de comunicarse, etc. Así también, menciona que los Smartphones que presentan nuevas aplicaciones para los individuos aumentan las formas de interactuar, pero también los restringe, ya que esta misma tecnología puede utilizarse como arma de control social y como medio de resistencia; siendo así, que los efectos beneficiosos conllevan también a consecuencias negativas.

Bedoya, Pérez Granda y Jiménez (2013), observan cómo es que el abuso de los Smartphones ocasiona ciertos comportamientos en sus usuarios, reflejándose en manifestaciones sociales de mayor impacto, promoviendo necesidades personales y colectivas en el acceso de información. Estos comportamientos socio-comunicativos tienen a los Smartphones como dispositivos de vínculo en el espacio social y son producto de la modificación en las formas de trabajar, consumir, y socializarse. Además, se comenta sobre la convergencia de tareas que antes eran exclusivas de las otras pantallas como la computadora o la televisión. Esta convergencia es la que muestra cómo los Smartphones han transformado las maneras sociales de interacción.

Turkle (2011) se pregunta sobre quién pensaría que una pequeña luz roja (del BlackBerry) que indica que una persona tiene un mensaje en su celular podría llegar al punto de volver "loca" a la gente. Ella nota que las personas se vuelven "tan locas" que inclusive si están en el auto y saben que no pueden leer y conducir a la vez, continúan con el timón en la mano a $100 \mathrm{~km}$ por hora, sobre todo si están en carretera y a la vez intentan leer el mensaje o contestar la llamada o contestar el mensaje escribiendo. Todo ello, aun sabiendo que existe un gran riesgo para sí mismo y para otras personas que puedan encontrarse dentro del auto e ese momento. Para esta autora, la exploración de la identidad se da actualmente por medio de Facebook y otras redes similares, esto afecta severamente el desarrollo del individuo. Actualmente, al aumentar el "contacto con amistades" en vez de afrontar las propias emociones, las publican en alguna de estas redes y las evalúan según las respuestas o comentarios de sus amigos. Las vidas 
de estos sujetos se experimentan a través de una identidad "online", por medio de avatares o perfiles de Facebook.

Asimismo, refiere que la vida de esta manera es considerada por ellos como "más grata"; puesto que, el internet les brinda un sentido de control. Las relaciones se reducen tan solo a lo que les da satisfacción; ya que, tienen la opción de descartar mensajes o eliminar lo que no les gusta. Sin embargo, "este tipo de conectividad está dejando a la gente con un sentimiento de soledad", están interactuando con "gente" sin realmente desarrollar relaciones verdaderas. Toda esta tecnología implica el uso de bastante tiempo de cada individuo; por tanto, el tiempo para pensar, reflexionar, estar a solas, etc...se deja de lado. Las personas empiezan a usar a otras para validación y no para establecer verdaderas relaciones; cuando esto sucede, en realidad están seleccionando y escogiendo pequeñas partes de uno para usar y responder a ello. No es una completa exploración de otra persona, sino que se está convirtiendo a la otra persona en parte de un objeto; es decir, se está utilizando a las personas como medio y no como fin.

Refiere que los adolescentes y jóvenes de ahora se siguen de ideas como: "para qué hablar, si puedo enviar un mensaje de texto" o "para qué leer un libro, si puedo jugar un videojuego". De esta manera, se llega a la idea de "por qué molestarse en conocer nuevos amigos si puedo seguirlos en Facebook o Twitter”.

Menciona que en el mundo occidental se ha vuelto muy común ver escenas; como por ejemplo, una en la que cada uno tiene su celular al lado y parece estar más pendiente de una llamada o de un mensaje escrito que de otra cosa. También se ve a una madre leyendo un cuento infantil a su hijo y de nuevo, el celular a su lado. Es en estos casos, que el niño tiene la impresión de que no es importante para la madre y aprende que la atención nunca es total; lo cual, puede afectar en sus relaciones sociales. Estos niños anhelan la atención, pero desarrollan creencias en las que para muchos de ellos una conversación telefónica es muy íntima e importante; por tanto, prefieren un mensaje de texto antes que una llamada o cara a cara. Afirma entonces que esos niños se sienten confundidos. Concluye que están tan juntos que lo único que pueden hacer es escribirse mediante mensajes en el celular, ya que los Smartphones están convirtiendo, a pasos agigantados, en privados los espacios públicos. Por un lado, están 
esos adolescentes que tienen una vida muy parecida a cómo viven su vida los adultos: se despiertan por la mañana y tienen 500 e-mails y 100 mensajes de texto, y verdaderamente no tienen tiempo de hacer otra cosa que no sea contestar a los e-mails y SMS. De forma que la autora concluye que la vida de los usuarios se convierte en puramente reactiva, esto significa que no se sienten solos pero tampoco se sienten conectados". Para lo que seguramente no tienen tiempo es para experimentar la soledad.

Comenta que una de las cosas más importantes que las personas están perdiendo es la posibilidad de estar solos de una forma confortante. Ello se puede observar en la idea de la autora sobre los usuarios; si no saben cómo estar solos, todo lo que podrán obtener en realidad es la misma soledad. Si no se enseña a los niños cómo estar a solas con uno mismo, todo lo que pueden hacer es tener soledad al final, ya que no aprendieron nunca a permanecer y disfrutar solos.

Finalmente, cuando se refiere a una solución, afirma que no se puede quitar de encima ninguna de las tecnologías, sino que se debe tener en cuenta que esta va a desarrollarse cada vez más y más bien, todos aquellos a quienes les afecta y les afectará en el futuro deben estar preparados para afrontarla; de esta manera, se estará preparado para usar el Internet en la forma y en la medida en que realmente se necesite; y así, se podrá quitar la luz roja del BlackBerry".

Según Ron et al (2013), en los últimos años, una consecuencia del abuso de los Smartphones es también la pérdida de la intimidad, lo que se refleja en la manera en que las nuevas tecnologías afectan al concepto de amistad. Esto se debe a que existe un riesgo importante de confundir los cientos de contactos que se tienen hoy en las redes con los que realmente son amigos de verdad. En muchos casos, se encuentra que se comparte información íntima con muchos contactos de las redes sociales, perdiéndose así lo valioso de proteger la intimidad y arriesgándose a dejar de ser los dueños de su propio futuro. Todo aquello que se hace por medio de las redes sociales queda de algún modo grabado. Siendo así, que cuando se esté en la búsqueda de un trabajo o cualquier otra situación, haya personas que tengan dos biografías diferentes sobre uno mismo, la del mundo físico y la del mundo digital. 
Recientemente se ha hecho a la población diversas advertencias sobre el peligro que pueden traer estas tecnologías (como el internet, Smartphone, entre otras), ya que presentan un alto potencial adictivo y ya existen centros de rehabilitación para estas adicciones que se están adaptando a dichas necesidades. La adicción más conocida es el internet, que podría encajar en lo que se llama últimamente: "adicción sin sustancia" (en la que existen semejanzas con los que son considerados adictos a sustancias porque en ambas existe una falta de tolerancia, dependencia y falta de abstinencia con patrones conductuales des adaptativos que son consolidados y repetitivos). Se comenta también, que cualquier persona es susceptible de engancharse con estos aparatos; sin embargo, la población más vulnerable son los adolescentes.

Dichos adolescentes son más vulnerables ante el uso en demasía de estos aparatos, ya que les permiten comunicarse desde el anonimato y mostrarse como realmente son y lo que realmente piensan. Se comenta que en cuanto a la comunidad psicológica, se está pensando en colocar dicho acontecimiento en los manuales de patologías. Además, existen ciertos tips, como: la pérdida de control ante el impulso de utilizar el aparato, la pérdida de noción sobre la cantidad de tiempo que lo usa, la interferencia en su vida social/ laboral/ personal, deseo intenso de entrar a internet o ver el celular, placer intenso al hacerlo, entre otros, para identificar la adicción. Todo ello, causa falta de sueño y por tanto fatiga; debilitación en el sistema inmunitario y deterioro en la salud (Suite y French, 2013). 


\subsection{Rendimiento Académico}

\subsubsection{Definición de Rendimiento Académico}

Se define el rendimiento como un producto o utilidad que rinde o da alguien o algo. Mientras que el término académico se define como relativo a centros oficiales de enseñanza; curso, traje, expediente, título académico (Velezmoro, 2007).

Existen ciertos factores que influyen en el rendimiento académico. La inteligencia y las facultades especiales (la actividad, el esfuerzo, los métodos de estudio y los factores ambientales). Es por ello, que el éxito en los estudios no solo depende de la inteligencia y del esfuerzo; sino también, de la eficacia de los métodos de estudio, así como los hábitos que un estudiante ha desarrollado en su experiencia educativa. Por ello, indica que en la evaluación del rendimiento académico se utilizan métodos desde la apreciación directa hasta la aplicación de pruebas tipificadas que permiten un enjuiciamiento con mayor objetividad, gracias a la tipificación de éstas. Asimismo, la calificación que se obtiene de las pruebas de rendimiento académico cuenta con una función valorativa, ya que muestra las debilidades y fortalezas del alumno en el aprendizaje (Fernández, 1990).

\subsubsection{Relación entre Rendimiento Académico y Smartphones}

Ron et al (2013), comentan que es importante adaptar los contenidos y cursos de estudio a la tecnología de hoy en día. Esta incorporación debe hacerse desde el profesor y junto con él utilizar recursos audiovisuales para que el aprendizaje sea una actividad compartida entre el profesor y el alumno y se desarrolle de forma natural. Un profesor siempre será un profesor; ya que su labor es la de enseñar, ayudar y guiar. Actualmente, los profesores ya no se consideran, como antes, los dueños absolutos del conocimiento. Sin embargo, siguen siendo quienes deben conducir a los niños o 
jóvenes al conocimiento, y lo pueden hacer como lo han venido ejerciendo solo que con las nuevas tecnologías.

Quiroz (2001), refiere que hoy en día existe mucha sobrevaloración de la información trabajada en los centros de estudios, ya que vivimos en una sociedad de información y abundancia informativa, en la que se piensa que mientras más información posea una persona, mayor será su desarrollo de la razón; por lo tanto, las personas serán más eficientes. En realidad hay una diferencia entre el conocimiento y la información. El conocimiento es la reflexión sobre la información, es aquello que impacta en el rendimiento académico, es la capacidad de discernir y discriminar la información que se tiene. Ello implica el poder ordenar y jerarquizar toda la información que se recibe para luego por medio del conocimiento que se tiene se pueda aprovechar la información. Por tanto, cabe recalcar que existen dos puntos de vista sobre la relación entre la educación y la tecnología; los que consideran que la tecnología es la solución a los problemas de educación facilitando los procesos de aprendizaje, mientras que otros rechazan la tecnología en el campo educativo porque la consideran un atentado contra la palabra, la lectura, el libro, la socialización, el rendimiento académico y la identidad cultural.

\subsubsection{Consecuencias del uso de los Smartphones en el Rendimiento Académico}

Actualmente está cambiando la forma en la que se están dictando las clases, la forma de entender y aplicar los recursos educativos utilizando la tecnología. Lo importante de esto es que los profesores y los alumnos desarrollen la mentalidad y herramientas necesarias para poder utilizar las nuevas tecnologías y aplicaciones adecuadas (Ron et al 2013).

Según Quiroz (2001), es notorio que el entorno tecnológico actual crea condiciones nuevas para el desarrollo en la educación. Actualmente, los jóvenes poseen una cultura audiovisual que les permite desarrollar habilidades relacionadas a un tipo de pensamiento divergente y a la vez a un desarrollo de pensamiento visual, todo ello distinto de las generaciones anteriores, en las que no se observaba lo aquí mencionado. 
Los medios han evolucionado y derribado fronteras geográficas porque han unificado las experiencias y se han universalizado muchas prácticas. Esta es la razón principal por la que es necesario darse un tiempo para reflexionar y cuestionarse; lo cual es difícil hoy en día debido a que la velocidad de las redes y del internet es muy rápida como para detenerse a reflexionar.

Ron et al (2013), afirman que los Smartphones pueden utilizarse para enseñar y aprender, pero son vistos como un aparato menos didáctico y un posible generador de situaciones conflictivas. Comenta la autora que se realizó una investigación en Latinoamérica y España, en la que encuestaron a más de 200,000 niños de colegios diversos; pudiendo observarse cuál es la causa del fracaso escolar tras el uso indebido del Smartphone. El resultado fue que los niños esperaban por las noches que sus compañeros de clase se conecten a internet para enviarse trabajos o para pasar tiempos de ocio conversando, en los que se quedaban hasta las 3 de la mañana aproximadamente, por lo que en la clase al día siguiente se quedaban dormidos y en la tarde no pueden estudiar por falta de concentración y sueño; siendo así, que obtenían bajas notas en sus cursos.

En la educación se producen varias transformaciones. Por ejemplo, cambia el sentido de saber y aprender en tiempos en que lo local y lo global no tienen relación o están mucho más vinculados. Además, hay una estrecha relación entre conocimiento y entretenimiento. En realidad, la percepción del tiempo y espacio se altera y se pierden las experiencias e identidades; el pasado se debilita y desaparecen las esperanzas de un futuro mejor frente a un presente con muchas discontinuidades. La educación tradicional se debilita en un tiempo cuya velocidad requiere nuevas actitudes. Ello se debe a que actualmente, el estudiante pasa por un tiempo y espacio en donde no necesita una guía preestablecida (Quiroz, 2001).

Otra posible consecuencia es que en muchos casos los adolescentes no logran separarse de sus padres; debido a que, siempre están conectados con ellos a través de sus Smartphones. Esto estorba el aprendizaje sobre cómo funcionar en el mundo de forma independiente y de cómo establecer su propia autonomía (Turkle, 2011). 


\section{CAPÍTULO III: OBJETIVOS}

- Describir la influencia del Smartphone en el rendimiento académico de estudiantes universitarios.

- $\quad$ Conocer las consecuencias del uso del Smartphone, en el rendimiento académico de estudiantes de ambos géneros pertenecientes a los últimos cuatro ciclos de su carrera universitaria.

- Identificar las razones que generan la necesidad de utilizar el Smartphone.

- Describir los beneficios y perjuicios del uso del Smartphone en el rendimiento académico de los estudiantes universitarios. 


\section{CAPÍTULO IV: MÉTODO}

\subsection{Tipo y diseño de investigación}

Esta investigación se realizó mediante un tipo de estudio exploratorio y descriptivo. Ello se debe a que el presente tema ha sido poco analizado porque es reciente en el campo estudio. De este modo, esta investigación busca obtener un mayor conocimiento sobre esta problemática. Además, presenta un alcance descriptivo, ya que especifica ciertas características importantes propias de la influencia de los Smartphones y hasta se pueden observar tendencias respecto a las conductas y respuestas obtenidas ante dicho dispositivo.

Según Hernández, Fernández y Baptista (2014), los estudios exploratorios son aquellos en los que el objetivo es examinar algún tema o problema de investigación que ha sido poco estudiado y sobre el que se presentan muchas dudas. Este tipo de investigaciones se da cuando se pretende analizar fenómenos desconocidos o nuevos. En cuanto a los estudios descriptivos, pretenden especificar las propiedades, perfiles y características de personas, grupos, comunidades, procesos, objetos o cualquier objeto que pueda ser analizado. Por tanto, se desea conseguir información de forma independiente o conjunta sobre los conceptos o variables que se desean estudiar.

Se utilizó el método fenomenológico, ya que la información se obtuvo de los fenómenos vividos por estudiantes universitarios cursando los últimos 4 ciclos de sus carreras, que utilizan los celulares con servicio de internet a lo largo de la vida académica a través de la percepción y los significados que ésta despierta en cada conciencia, de modo que se pueda describir, comprender e interpretar dicha información; permitiendo develar aquellas influencias que el uso de este aparato tiene en el rendimiento académico de los estudiantes.

Arroyo y Merlino (2009), definen el método fenomenológico como la ciencia que trata de descubrir las estructuras esenciales de la conciencia de las personas, es decir que se basa en experiencias directas y se impone con evidencia irresistible. Este método, se centra en el estudio de esas realidades vivenciales que son poco comunicables, ya que solo pueden ser captadas desde el marco de referencias del sujeto que las vive y 
experimenta; por ende, son determinantes para la comprensión de la vida psíquica de cada persona. Afirman que la fenomenología no desea excluir de su objeto de estudio nada de lo que se presenta en la conciencia de cada sujeto; por el contrario, desea aceptar todo lo que se presenta tal como se presenta.

\subsection{Participantes}

La población para llevar a cabo esta investigación son jóvenes universitarios hombres y mujeres, que posean un Smartphone, pertenecientes a los últimos cuatro ciclos de universidades de Lima Metropolitana, de edades entre 21 y 24 años, y pertenecientes a los niveles socioeconómicos "medio alto" y "alto".

El tipo de muestra que se utiliza en la presente investigación es el muestreo intencional homogéneo, ya que se buscaron participantes que presenten las características antes mencionadas; lo que permite que haya mayor información sobre el uso de celulares con servicio de internet, basada en un mismo grupo social.

Este tipo de muestreo consiste en que las unidades a seleccionar cuentan con un mismo perfil o características, o comparten rasgos similares. Por tanto, el objetivo de utilizar este tipo de muestreo es centrarse en el tema a investigar o resaltar situaciones, procesos o episodios en un grupo social (Hernández et al, 2014).

La manera en la que se reclutó a los participantes fue intencional y con el método de "Bola de Nieve", ya que al buscar participantes con las mismas características, quién mejor que los mismos participantes para indicar otros sujetos que cumplan con estas características y a la vez puedan participar de la investigación.

El término "Bola de Nieve" se refiere a la identificación de aquellos participantes claves para la investigación, ya que este método consiste en preguntar a los participantes si conocen otras personas (con las mismas características necesarias para esta investigación) que puedan aportar datos más amplios. Ello hace que se forme una especie de red (o bola de nieve) que va haciéndose cada vez más grande y se va contactando a la población con las características esperadas (Valderrama, 2002).

Se entrevistó a 15 estudiantes universitarios, teniendo en cuenta el punto de saturación (también llamado principio de saturación) al momento de realizar las entrevistas. Este principio, consiste en el detenimiento de la aparición de nueva 
información en la recolección y análisis de datos, ya que estos comienzan a repetirse y no aparece nueva información para crear nuevas categorías. Por ende, si a medida que va incrementándose la muestra no aparece información diferente a la ya obtenida, se dice que la muestra se ha saturado (Katamaya, 2014).

Para tener un mejor detalle de los aspectos demográficos de la muestra, se realizó el siguiente cuadro con el total de los colaboradores entrevistados (15 personas).

\section{Tabla 1}

Datos Demográficos de los Colaboradores Entrevistados

\begin{tabular}{|c|c|c|c|c|}
\hline Género & Edad & $\begin{array}{c}\text { Provincia } \\
\text { donde reside }\end{array}$ & $\begin{array}{c}\text { Ciclo } \\
\text { universitario } \\
\text { actual }\end{array}$ & $\begin{array}{c}\text { Facultad en la que } \\
\text { se encuentra }\end{array}$ \\
\hline Femenino & 22 & Lima & 8 & Psicología \\
\hline Femenino & 22 & Lima & 8 & Psicología \\
\hline Femenino & 23 & Lima & 10 & Administración \\
\hline Femenino & 21 & Lima & 8 & Ciencias de la Comunicación \\
\hline Masculino & 24 & Lima & 10 & Economía \\
\hline Masculino & 24 & Lima & 10 & Administración y Finanzas \\
\hline Femenino & 23 & Lima & 9 & Publicidad y Marketing \\
\hline Femenino & 23 & Lima & 9 & Ciencias de la Comunicación \\
\hline Masculino & 21 & Lima & 8 & Música \\
\hline Masculino & 22 & Lima & 8 & Ingeniería de Sistemas \\
\hline Masculino & 24 & Lima & 10 & Ciencias de la Comunicación \\
\hline Femenino & 23 & Lima & 10 & Derecho \\
\hline Femenino & 22 & Lima & 9 & Publicidad y Marketing \\
\hline Masculino & 22 & Lima & 10 & Publicidad y Marketing \\
\hline Masculino & 23 & Lima & 10 & Psicología \\
\hline
\end{tabular}




\subsection{Técnicas de recolección de datos}

Para la presente investigación se utilizó un método cualitativo; siendo así, que al momento de recolectar la información se empleó la técnica de la entrevista a profundidad semi-estructurada. Se escogió esta técnica, ya que al ser una investigación que pretende informar y describir; el hecho de que el entrevistador pueda añadir preguntas adicionales, a las establecidas previamente, en el transcurso de la entrevista; permite obtener mayor información, detalle y perspectivas sobre el tema a tratar.

Esta entrevista, consta de treinta y siete preguntas guía que abarcan las áreas del uso del servicio de internet en el Smartphone y el rendimiento académico que presentan los alumnos de los últimos ciclos de sus carreras pertenecientes a distintas universidades de Lima Metropolitana.

La entrevista cualitativa semi-estructurada se basa en una guía de asuntos o preguntas y el entrevistador tiene la libertad de introducir preguntas adicionales para precisar conceptos y obtener mayor información sobre los temas deseados durante la entrevista; es decir, no todas las preguntas están predeterminadas (Hernández et al, 2014).

\subsection{Procedimiento de Recolección de datos}

Para la recolección de datos, se siguieron los siguientes pasos que ayudaron a conseguir dicha información. En primer lugar, la investigadora ingresa a las universidades escogidas para realizar la investigación y pregunta a los mismos estudiantes en qué lugar podría encontrar a la población con las características deseadas, de este modo se acerca a dicho entorno y pregunta si desean participar de una entrevista, explicándoles la finalidad de ésta.

En segundo lugar, se coordina directamente con el estudiante seleccionado, el momento y lugar en el que tenga disponibilidad para realizar la entrevista. En tercer lugar, se le otorga el formato del Consentimiento al participante para que pueda leer el documento y firmarlo, autorizando así su participación en parte del procedimiento de la investigación. En cuarto lugar, se realiza la entrevista en la fecha y hora pactada con anterioridad. En quinto lugar, se agradece al estudiante entrevistado por el tiempo y se le despide cordialmente. En sexto lugar, se analiza la entrevista creando códigos y subcódigos o en todo caso, si ya están creados, se clasifica las respuestas de cada entrevistado 
en dichos códigos. En última instancia, se realiza una discusión sobre los resultados encontrados, finalizando así, en las conclusiones y recomendaciones en lo que respecta a la investigación en sí.

\subsection{Estrategias de análisis de datos}

A lo largo de la presente investigación se realizan entrevistas a diferentes estudiantes universitarios; luego de cada entrevista se procede a transcribir la información obtenida y los datos se van codificando, creando categorías de información.

Una vez que se tienen las categorías de información establecidas; es decir, cuando se produce el principio de saturación, se procede a elaborar las relaciones entre los objetivos de la investigación y la información categorizada; de modo que se pueden encontrar patrones, similitudes y diferencias entre en dicho análisis.

Finalmente, en base a la información obtenida y las relaciones encontradas, se realiza la discusión, en donde se relacionan los resultados que se obtuvieron del análisis de datos y los objetivos que se esperaban hallar con la presente investigación.

Por tanto, se organizan los datos recogidos, se transcriben a texto y se codifican. La codificación tiene dos planos: el primero, en el que se generan unidades de significado y categorías. Segundo: emergen temas y relaciones entre conceptos.

Se afirma que el análisis de datos en las investigaciones cualitativas consta de una serie de pasos, los cuales no necesariamente van en línea recta, sino que es una línea en continuo movimiento, que puede ir y regresar diversas veces. Por tanto, los autores dividen en tres partes esta sección de análisis.

Primero, la etapa de recolección de datos; en la que la información obtenida es por medio de observaciones, pláticas (primero informales y luego dirigidas), anotaciones de estas y datos obtenidos por medio de entrevistas/grupos focales/observación/etc. En segundo lugar, están las tareas analíticas, en las cuales se realizan continuas reflexiones entre los datos obtenidos y sus impresiones sobre el ambiente, analizar correspondencia entre los primeros y los nuevos datos y utilización de diversas técnicas, como: teoría fundamentada, matrices, diagramas, mapas conceptuales, etc. La tercera y última etapa cosiste en elaborar los resultados, aquí se deben encontrar similitudes y diferencias entre 
los datos, significados, relaciones y patrones; así como, generar sistemas de categorías, relaciones, hipótesis y teoría (Hernández et al, 2014). 


\section{CAPITULO V: RESULTADOS Y DISCUSIÓN}

A continuación, se presentan los resultados a partir de las categorías que fueron elaboradas luego de realizar el análisis con toda la información recolectada para la presente investigación. Antes de ello, se realizará un breve resumen en el que se relacionan los resultados analizados con los objetivos planteados.

En general, se puede ver que los resultados responden a los objetivos planteados en esta investigación. Como primer objetivo, se deseaba conocer las consecuencias del uso del Smartphone en el rendimiento académico de los estudiantes que se encuentran en los últimos cuatro ciclos de sus estudios. Respecto a este objetivo, se encontró que existe una dualidad por parte de los mismos estudiantes, ya que refieren que el uso del dispositivo, por un lado no afecta su promedio académico. No obstante, sí afecta el tiempo que dedican para diversas actividades académicas; sean: trabajos individuales o grupales, estudio y concentración, lecturas, etc.

A continuación, se presentan los resultados a partir de las categorías que fueron elaboradas luego de realizar el análisis con toda la información recolectada para la presente investigación.

Es decir, los mismos estudiantes se dan cuenta de que una consecuencia positiva del uso de este dispositivo es que su promedio no se ve alterado o influenciado por el uso de éste; sin embargo, se encuentra una consecuencia negativa al percatarse de que el tiempo que empleaban inicialmente para estudiar o hacer trabajos universitarios o cualquier actividad que tenga que ver con el ámbito académico, era menor al que emplean ahora que utilizan a la vez el Smartphone. Ello quiere decir, que con el Smartphone tienden a distraerse más y a perder más rápidamente la concentración en la actividad académica que están realizando.

Ello, se encuentra reflejado en la teoría de Quiroz (2001), quien refiere que existen dos puntos de vista sobre la relación entre la tecnología y la educación. Por un lado, están aquellos que consideran que la tecnología facilita de tal forma el aprendizaje que es la solución a los problemas de educación en el país. Sin embargo, la contraparte rechaza la tecnología en el área educativa porque la consideran un atentado contra la lectura, la socialización, el rendimiento académico, entre otros. 
Otra consecuencia que se encontró es que el uso del Smartphones produce un ahorro de tiempo en cuanto a la búsqueda de información y coordinaciones académicas, facilitando así la rapidez en la obtención de respuestas en ambos casos.

Como segundo objetivo se planteó el poder identificar las razones que generan en una persona la necesidad de utilizar su Smartphone. En esta investigación, se encontró que existe una fuerte necesidad por parte de los usuarios de estar constantemente conectado en el celular o simplemente revisándolo cada cierto tiempo, verificando que esté siempre a la mano.

Esta necesidad se ve fundamentada en primer lugar por el mismo hecho de sentirse comunicados con las personas de su entorno cercano, es decir: familia, amigos, compañeros de trabajo y la pareja. Mostrando a la vez, estar disponibles para ellos en cuanto lo requieran. Sobre este punto, se piensa mucho en la posibilidad de una situación de emergencia, por lo que la necesidad de estar con el celular al lado es más necesaria aún.

Esta necesidad de sentirse comunicados es a la que se refieren Lejoyeux y Adés (2003), cuando comentan que este dispositivo puede llevar a una dependencia porque es una necesidad para el usuario y los efectos negativos están estrechamente relacionados con su utilización; es por ello, que algunos desarrollan una necesidad de estar en constante conexión con otras personas, lo que es posible a través del celular y va mucho más allá de la necesidad de estar en contacto con otros.

En segundo lugar, esta necesidad de estar siempre con el celular a la mano se da debido a un tema de aburrimiento u ocio y a la multifuncionalidad que brinda este dispositivo, la cual encaja perfectamente en dichos momentos de aburrimiento u ocio. Ello quiere decir que, sea que los usuarios estén en sus clases en la universidad o en sus oficinas de trabajo, cada vez que se encuentran aburridos o tienen algún tiempo libre, sienten la necesidad de utilizar su Smartphone. De este modo, gracias a la multifuncionalidad del dispositivo, los estudiantes emplean estos momentos en sus celulares realizando diversas tareas a la vez.

Sobre este tema, Castro (2012), refiere que el celular, al haberse insertado tan rápidamente en la sociedad como una forma de acceso a información y diversos contenidos; es que se ha innovado de tal manera en los dispositivos portátiles, que es por ello que hoy en día son multifuncionales y permiten: enviar sms, tomar fotos, escuchar música, navegar por internet, enviar mails, usar GPS, descargar juegos, organizar actividades del día, chequear 
cuentas bancarias, escribir en blogs, entre otras funciones. Todo ello, con el fin de llenar esos espacios libres.

Así también, Schmidt y Cohen (2014), comentan sobre la multifuncionalidad del Smartphone, refiriendo que estos brindan la posibilidad de acceder a un diagnóstico básico sobre enfermedades, o lo utilizan como despertador en las mañanas, como block de notas, recordatorios de eventos o actividades, GPS, cámaras y grabaciones de audios, páginas como Twitter o Facebook o la Web, etc.

En tercer lugar, los participantes muestran una fuerte necesidad de tener su Smartphone consigo al indicar todos aquellos sentimientos negativos o desagradables que les produce el hecho de no tenerlo al lado. El simple hecho de que les genere frustración, ansiedad o un sentimiento de ausencia; significa que poseen una estrecha relación con su dispositivo y que, por ende no están dispuestos a separarse de él.

Respecto a esta necesidad encontrada, los autores Ron et al (2013), mencionados anteriormente, resaltaron este aspecto en cuanto a los usuarios de Smartphones, ya que indicaron que estos al darse cuenta de que no tienen su celular sienten mucha angustia y ansiedad. Es por ello, que hacen un llamado a reflexionar sobre el tiempo de conexión que mantiene hoy en día un usuario en su Smartphone.

Uno de los criterios representativos de la adicción que mencionan los autores Jiménez-Murcia y Farré Martí (2015), es la abstinencia, es decir que el usuario presenta malestar cuando se le interrumpe la utilización del dispositivo con internet, el cual se puede mostrar como enfado o ansiedad o agresividad, etc.

En cuarto y último lugar, los estudiantes muestran la necesidad de estar con su Smartphone al momento en que prefieren y escogen utilizarlo como el medio comunicador de temas personales; es decir, temas que quizá sería mejor conversar en persona, ya que se pueden prestar a malos entendidos o discusiones innecesarias. Así mismo, ellos eligen el Smartphone para comunicar ciertos temas que podrían generar una reacción negativa del interlocutor o generar una situación incómoda. Por lo tanto, necesitan su Smartphone para refugiarse detrás de una pantalla y así evitar situaciones incómodas o reacciones negativas de otras personas.

Sobre esta cuarta necesidad, Schmidt y Cohen (2014), comentan que los Smartphones apoyan con la creación de nuevas oportunidades en la educación; así como en la asistencia 
sanitaria y seguridad, ofrecen oportunidades comerciales, entre otras. No obstante, resaltan que el internet produce cierto anonimato que genera una especie de aislamiento protector que incentiva a continuar en el anonimato a los usuarios.

El tercer objetivo planteado fue describir la influencia del Smartphone en el rendimiento académico de los estudiantes. Las respuestas a este objetivo fueron las que marcaron mayores controversias a lo largo de la investigación, ya que los mismos estudiantes presentan posturas antagónicas sobre ello.

Por un lado, los estudiantes encuentran una influencia positiva del Smartphone sobre el área académica, ya que éste les permite realizar diversas funciones que les facilita en cuanto al rendimiento universitario; tales como: la búsqueda de información, envío de trabajos, revisión de material de clase, entre otras.

Sin embargo, todos los participantes afirman que el uso del dispositivo sí interfiere con su concentración en el proceso de estudio; y por ende, en el tiempo que dedican a los trabajos (sean individuales o grupales) o al mismo estudio. Ello se muestra cuando los estudiantes planean un tiempo aproximado de estudio o para realizar un trabajo y finalmente se toman un tercio o la mitad más del tiempo que se pensó en un inicio porque perdieron su concentración debido a que les llegó alguna notificación o simplemente ellos decidieron hacer un alto en su estudio para revisar su Smartphone, ya que el tenerlo al lado les genera una especie de tentación a la cual no parecen ser lo suficientemente fuertes para resistirla.

Estas revisiones esporádicas del Smartphone las comentaron también los autores Lejoyeux y Adés (2003), quienes afirman que este dispositivo es utilizado hoy en día básicamente para consultar dónde se encuentra uno y con quién, porque los usuarios consultan el celular decenas de veces al día y generalmente son mensajes sin contenido.

También, se puede ver que esta distracción de los usuarios por propia voluntad; es decir, sin que les haya llegado una notificación, se da por una intensa curiosidad con la que muestran una actitud constante de saber y ver lo que hacen los demás. Ello está convirtiendo a las redes en una especie de "gran hermano" digital, donde todos pueden observar la vida de otros y hacerlo por largos períodos de tiempo (Ron et al 2013).

Este percance en cuanto a la falta de organización para estudiar en el tiempo planeado inicialmente, se puede ver en uno de los criterios representativos de la adicción que presentan Jiménez-Murcia y Farré Martí (2015), es el de la utilización del Smartphone es mayor a lo 
planeado, por lo que la falta de control sobre el tiempo de conexión en el celular, es un punto importante a tomar en cuenta.

Finalmente, el último objetivo fue la identificación de la relación entre el usuario y el uso del Smartphone es percibida por los estudiantes como beneficiosa o perjudicial. Sobre ello se encontró que los participantes piensan que el dispositivo es beneficioso por un lado, ya que les brinda herramientas e información de manera precisa y rápida. Así mismo, les

permite realizar coordinaciones grupales y facilita el envío de trabajos; por lo que, hay una mayor efectividad en cuanto a los resultados académicos.

No obstante, los mismos estudiantes perciben que el Smartphone es perjudicial para su concentración al momento de realizar trabajos, estudiar o leer materiales universitarios. Siendo ello, lo que lleva a un mayor gasto de tiempo, el que quizá sin la presencia del dispositivo podría ser bastante menor.

Justamente, sobre el tiempo que los estudiantes se mantienen conectados al Smartphone, Jiménez-Murcia y Farré (2015), refieren que el 85\% de usuarios se conecta a internet a través de su Smartphone debido al bajo costo, las tarifas, entre otros. De ese 85\%, el $70.7 \%$ se conecta varias veces durante el día, el tiempo de uso diario que le da un $6.9 \%$ es de más de cuatro horas. Por tanto, se puede ver que existe un gran porcentaje de personas que pasan mucho tiempo conectadas a sus dispositivos.

\section{Categoría: Utilidad}

Se puede observar que los estudiantes utilizan el teléfono inteligente para mantenerse al tanto sobre las noticias universitarias; así como, sobre cualquier cambio o modificación que se realice a nivel académico. Así mismo, se evidencia que el Smartphone funciona bastante bien como soporte informacional y herramienta de estudio, la cual permite cualquier organización y/o coordinación académica. Finalmente, todo lo antes mencionado es posible en un corto período de tiempo, gracias a este dispositivo.

"Porque puedo entrar a la página de la universidad y ver mis clases, mis horarios, el correo de la u, jtodo! También me permite comunicarme con gente de mi grupo de trabajo...con el whatsapp o Facebook" 
“Asu...imprescindible totalmente...te ayuda desde poder revisar tu...no sé, te avisan que ya salió la nota del examen tal, y así puedes revisar la nota inmediatamente a través de tu celular y si...si no alcanzaste la nota de repente poder tener la oportunidad de hacer un reclamo o algo así inmediatamente y no dejar que pase el tiempo. Aparte, eh...es súper práctico...de no tener que llevar toda una laptop, sino que buscas la info desde tu cel, o sea... agiliza el tener que coordinar determinadas cosas con...con personas con las que tengo que hacer tareas o trabajos, una cosa así. Igual, uso más el Smartphone...porque entro a bibliotecas virtuales de universidades reconocidas; como: el IS , eh...cuál más, Harvard Busines Review, artículos sobre periódicos reconocidos también, Gestión...eh....ese tipo."

"Yo uso bastante el correo de la u. Bueno, uso el Smartphone un montón porque tengo que hacer trabajos, coordinar con la gente, o sea ...todo, o sea...buscar información al paso, entonces te conectas mucho por esa parte, la parte tanto académica de buscar por ejemplo, no sé...cuando dice un profesor "busquen este libro" que no sé qué, ok...al toque busco el título y le hago un print screen y lo guardo y así...por ejemplo, eh...no sé por ejemplo una palabra que no tengo ni idea qué es a veces, entonces la busco, ya ok y sigo...conecto. De ahí, para hacer trabajos en grupo también es súper fácil organizar por ahí, ya todo el mundo se pone de acuerdo, nos encontramos a tal hora, entonces ya, quedamos chévere."

Otra utilidad que presenta el dispositivo móvil con servicio de internet y quizá la más importante de las funciones que posee es la de comunicación al instante. Se denota que esta función es la más utilizada por los estudiantes, la cual se puede dar de diferentes maneras (no siendo ninguna menos importante que otra), que son la comunicación escrita y la comunicación verbal; llegando con ambos tipos de comunicación no solo a Lima y provincias del Perú, sino a distintos países del mundo también. Ambos tipos de comunicación se pueden ver en lo que se refiere al ámbito académico, tal como se mencionó anteriormente; así como en lo que se refiere a sus vidas personales. 
"Te puedes comunicar con quien sea; por ejemplo, yo tengo un amigo en Miami y me comunico con él a través del whatsapp, o sea...puedes comunicarte en segundos. Por ejemplo, el Facebook lo uso para comunicarme con mis amigos, gente que no veo hace tiempo, o sea para mantener conexiones con varias personas en simultáneo, o sea puedes tener abiertas varias conversaciones y puedes como que...hablar en simultáneo en segundos...bueno, uso bastante el Facebook y lo miro a cada rato para ver qué hacen los demás, pongo a cada rato actualizar noticias, noticias noticias...para ver qué hacen los demás, no sé...es como que una adicción por así decirlo, por el hecho de tener el teléfono en la mano."

“...porque lo uso bastante para conversar con mi enamorado, con mis amigas y el grupo de mi familia que todo el día hablan (risas), básicamente eso. Reviso el Facebook, pero la mayoría del tiempo lo uso para conversar."

"Las aplicaciones que más uso son facebook, whatsapp, mail...las uso porque me divierten (risas) y siento que estoy más conectada con mis amigos Más que nada para hablar con la gente más cercana y creo que es un medio por el que puedes hablar con más gente a la vez y más fluido. Te avisa también cuando tienes reuniones sociales o...para enterarse de lo que pasa en el entorno. Mmm...en verdad uso las redes sociales para enterarme de lo que hace la gente que me interesa (risas) o conversar con ellos."

“...la posibilidad no solo de llamar, de mandar mensajes, sino ahora también de entrar a internet para principalmente redes sociales. Bueno, yo principalmente uso el Whatsapp como mensajes, audios, llamadas. Luego, lo uso para llamar (risas), uso eh...algunas redes sociales, poco, no mucho. Uso también Facebook."

“...de hecho sirve para ...eh...contactos, llamadas, comunicación, lo básico. Whatsapp. Facebook también, lo utilizo más como un método de comunicarme con aquellos contactos que hay en el mismo, mi correo personal y mi segundo correo personal para comunicarme con amigos o que me manden cosas o yo mandarles..." 
La utilidad lúdica es otra de las funcionalidades del Smartphone, la cual se puede ver en los estudiantes, cabe resaltar que son del género masculino, que dedican parte de su tiempo para estar en diferentes clases de juegos en sus dispositivos. La utilización del celular para jugar, se da como una manera enfrentar el tiempo de espera o aburrimiento que pueda presentarse en diferentes contextos o situaciones.

“¡Casi siempre! (risas) Mmm...juego cuando me aburre la clase o siento que ya sé lo que están explicando...y qué juego...candycrush (risas)...el jueguito de Facebook."

"Sí, tengo mi jueguito que se llama Clash of Clans, es de guerras entre clanes, construyes tu aldea y tienes que robarle a otras para tener recursos (...) es en línea...es más, incluso tengo mi grupo de Clash of Clans en Whatsapp también (risas)...y cuánto tiempo dedico a jugar...minutos...serán diez minutos, bueno... si estoy en clase no voy a estar más de una hora tampoco, diría que...diez minutos por cada hora y bueno, en mis breaks también"

“...algunos jueguitos para matar el tiempo en el micro (risas). Am...admito que sí, agarraré una media hora en total de todas mis clases para jugar. Usualmente en las noches juego más, ahorita mi computadora está malograda, por lo que mi única computadora es mi celular, así que en las noches es donde más lo utilizo para ver videos para jugar esos jueguitos no muy viciosos."

El Smartphone sirve también como un proveedor de diferentes servicios, así como de entretenimiento, ya que hace posible la instalación de ciertas aplicaciones que contienen diversos servicios de pago y regularizaciones o de movilidad. De la misma manera, cuenta con la posibilidad de tener aplicaciones sobre algún tema de interés para el usuario.

“Como por ejemplo Waze, que te ayuda con el tema del tráfico, acá en Lima. Eh...también hay aplicaciones con respecto a...si te gustan no sé, temas de futbol en mi caso, hay aplicaciones que te mantienen al tanto y te mandan información temas 
deportivos o temas de...de...cultura. Por ejemplo, yo sigo a una revista de Economist, donde te mandan artículos diarios y te mantienen al tanto también de las noticias a nivel macro con respecto a la economía."

“(...) también Waze, es una aplicación súper buena si es que tengo que ir a algún destino, aplicaciones que te pueden traer no solo beneficios informativos sino también otros beneficios como descuentos, promociones, estás más a la vanguardia con lo que pasa en el mercado. Instagram, Eh...otra aplicación, bueno Easy Taxi que es mi medio de transporte ahora (risas), Uso bastante Twitter, me sirve para enterarme de las noticias en el momento, al instante."

“Uso eh...cómo se llama esto... Google Maps, En mi caso, veo páginas de mi interés en general. Eh...veo, tengo aplicación de bancos para hacer mis pagos y todo (risas) y la bolsa también pues no...para estar enterado."

“...páginas de no sé...periódico... lo que te interese descargarte. Por ejemplo, lo que yo tengo de cajón en mi cel es el Comercio porque siempre leo los titulares y ya si me inyteresa algo entro y leo todo completo, pero siempre leo esto porque de hecho hay que estar informada (risas)"

Se sabe que todos los Smartphones cuentan con herramientas propias del dispositivo, las cuales son bastante utilizadas, tanto en diversos momentos como diariamente por los usuarios. Es así, que podemos observar que la utilidad de dichas herramientas es bastante diversa y se puede acomodar a los distintos perfiles de los usuarios. Sea que se necesite para iluminar, para capturar un momento o hasta un intervalo de tiempo, para organizarse en cuanto a la semana o mensualmente, para colocarse horarios, o hasta para guardar observaciones que no se desean olvidar, entre otros.

"Y el que dejo prendido es el del trabajo porque lo uso como alarma." 
“Eh...posibilidad de tomar fotos, ver videos, grabarlos y ponerlos en internet desde cualquier lado (risas), donde capte tu celular la señal, si es que tus megas te lo permiten (risas)"

“Un par de aplicaciones para hacer notas...básicamente de cosas que tengo que hacer o pendientes del trabajo y a veces de mis cursos"

Se evidencia que una de las utilizaciones que se le da al Smartphone es para fines laborales, en donde los usuarios le dan un uso oficinista; es decir, trabajan en los mismos programas que contiene una laptop, solo que a través de este dispositivo y hasta pueden enviar sus trabajos a otros usuarios utilizando las diferentes aplicaciones y plataformas que éste contiene. Así mismo, se sabe que no sólo se utiliza el dispositivo para temas de coordinación y comunicación de manera inmediata, como un fin en sí mismas. En realidad, se suelen realizar también, tanto las coordinaciones como la comunicación, como medios para un fin, que en este caso vendría a ser exclusivamente laboral. Tan es así, que inclusive puede ser entre dos personas o más a la misma vez; al punto de convertirse en una herramienta de trabajo exclusivamente.

"Para coordinar cosas del trabajo ...eh ...o sea temas relacionados con el trabajo. Ponte, cuando tengo que hablar con alguien de la oficina, avisar que me retrasé, así”

"Claro (risas) de hecho creo que un montón de gente lo usa por el tema del correo de la chamba pues, o sea...eh ...por lo menos yo sí (risas) y bastante, o sea, todo el día. De hecho creo que es una ayuda porque no tienes que llegar a tu ofi para ver el correo, sino que ya pues... ahí está todo el día a tu disposición y te mandan correos, respondes, te responden, te mandan cosas o tu mandas cosas a tus compañeros de la chamba, y así (risas).”

“Eh...bueno, al menos para mí se ha vuelto una herramienta de trabajo, eso sí. De hecho uso el cel más que nada como compu que otra cosa (risas), o sea ... ya el llamar o escribirme con mis patas o con quien sea ha pasado a un segundo plano (risas). Ahora es más que nada hacer wevadas en los archivos que me manden o modificar o completar info 
en Word o ppt, no es tan cómodo como una laptop pero igual pes no, de hecho puedes hacer tu chamba desde ahi tranqui (risas)."

\section{Categoría: Dependencia}

Uno de los temas más resaltantes sobre el uso del Smartphone es la dependencia que desarrollan los usuarios hacia este dispositivo. Existe la dependencia respecto al tiempo de uso que se le da, con la cual, los usuarios permanecen conectados a su Smartphone aproximadamente entre 6 y 8 horas diarias durante la semana, sin contar los fines de semana. Ello, se da al contar los minutos de cada vez que los usuarios utilizan su dispositivo; sea para responder algún tipo de comunicación o para simplemente satisfacer su necesidad momentánea de revisarlo "por si hubiese algo nuevo".

Tan es así, que los mismos usuarios consideran que el máximo tiempo que podrían permanecer sin su Smartphone es de una semana. Actualmente, los Smartphones, más que un medio de comunicación o una herramienta para diversas funciones, se han convertido en parte de un nuevo estilo de vida. Esto significa que se espera que cualquier persona cuente con un Smartphone para poder enviarle diversas cosas o se espera que cuente con las

aplicaciones y funciones necesarias de dicho celular para mantener una comunicación en el mismo nivel tecnológico

Sin embargo, se encuentra una contradicción algo difícil de comprender. Siendo así, que pese a que los usuarios refieren no poder ser capaces de permanecer mucho tiempo sin su celular por formar parte crucial de sus vidas, a la vez se sienten abrumados por la cantidad de información y estímulos que brota de este dispositivo, los cuales no les permite desligarse en tiempos de ocio o de relajo.

“'Todo el día lo uso! (risas) porque si no me siento incomunicada. Además es un vicio, no puedo dejar de mirarlo (risas) porque estoy hablando con mi enamorado, con amigos y estoy pendiente de lo que me dicen o tipo...tengo que contestar. (...) creo que pordría estar 
sin mi cel un día máximo ...y me sentiría mal (risas), como que algo me falta ;Qué horrible!"

“Creo que hoy en día...como ya dije, es un nuevo estilo de vida, la mayoría de gente que conozco....y yo (risas) vive usando sus aparatos todo el día mmm ...pero si es un día más relajado, converso con mis amigas, chismeo facebook (risas) así. Mmm ...en verdad dos veces me lo olvidé en mi casa y estuve sin el teléfono todo un día, las dos veces y no te voy a mentir que sentía la ansiedad por verlo (risas), pero conforme pasaron las horas, me acostumbraba, aunque siempre pensaba en el celular y me daba curiosidad tipo...quién me habrá escrito, qué me estarán poniendo, si tengo correos, y eso... Asu...mmm...(risas) mi vida sin smartphone...este...sí la veo media difícil (risas), pero no sabría si podría acostumbrarme o no...supongo que es algo que tendría que pasarme (risas)"”

"No tengo ni idea...posiblemente podrían ser cinco o seis horas al día. Eh...yo creo que de las 6 horas que puedo usarlo en el día, el $70 \%$ del uso es netamente trabajo y el otro 30\% es social. Ahora, si estoy de vacaciones, tranquilamente he estado 5 dias sin celular y he sido la persona más feliz del universo. Los primeros dos día, he estado totalmente tenso y ansioso por saber qué pasa, el tercer día he estado relajado y el cuarto día simplemente no quería revisar el celular. (...) Creo que, me conecto porque me escriben y por chequeos esporádicos, pero más por chequeos esporádicos. O sea como que suena una campanita en tu cabeza “cli-click” y te dice: Oye revisa tu celular, puede haber algo."

“Pucha (risas) tranquilamente podrían sumar seis horas...o hasta más (risas) porque puedo pasarme media hora tirada en mi cama, viendo el teléfono o una hora ... y en breaks de 10 minutos que lo cojo y luego lo vuelvo a coger, sí, tranquilamente podrían ser 6 horas al día. Si...sí claro, en la mañana, en la noche (...) Entonces estás en un momento no sé...yendo de un lugar a otro o estás caminando o esperando algo y automáticamente lo que quieres es ver el teléfono y no lo tienes y es como una necesidad de que te falta algo...sobre todo cuando ves que las demás personas están en esos momentos viendo sus teléfonos, la necesidad es aún mayor (risas) (...) mmm ...eh... creo que lo veo más por chequeos esporádicos porque ya hasta a veces creo que suena o que vibra y no ha sonado, 
no ha vibrado. Pero ya es como un tic que tengo que cogerlo y de mirarlo a pesar de que no ha sonado porque o creo o no sé, ya es involuntario."

"A lo que voy es que deshumanizan un poco. A veces uno está muy pegado a un Smartphone, como que es...la extensión de tu cuerpo, pero llega a ser tanto así que se vuelve parte de ti y ya dejas de ver como que el mundo real pues no. O sea, el contacto humano, estar en clase y prestar atención al profesor y lo que está diciendo mientras que estás con tu celular o haciendo cualquier otra cosa, creo que te aparta como que del mundo real también. A ver...fácilmente qué, podría estar conectada unas cinco horas al día, o sea juntas...sí, unas cinco horas o cinco horas y media (...) mmm...es que en verdad estaría dos o tres días sin celular."

Otra forma de dependencia que presentan los usuarios del Smartphone es según el momento en el que lo emplean, siendo importante resaltar que ninguno suele apagarlo por ningún motivo, ya que podría haber una emergencia o notificación importante que deba ser atendida en el momento. En general, se puede ver que lo utilizan básicamente para satisfacer sus momentos de aburrimiento. Dichos momentos, se presentan mayormente durante las clases en la universidad o durante el horario de trabajo o prácticas pre profesionales. Así mismo, se observa también que existe cierta dependencia en momentos de ocio, debido a que los usuarios cuentan con un tiempo libre y deciden utilizarlo en su celular, ya que de este modo sienten que el tiempo pasa más de prisa.

Los usuarios del Smartphone presentan dependencia en el momento en que se genera dentro de determinados contextos o situaciones, llegando a desarrollar patrones de respuesta ante estas situaciones, es decir conductas repetitivas en determinadas situaciones. Ello se traduciría en que los patrones de respuesta consisten en utilizar el dispositivo cada vez que un determinado tipo de situación se dé. Estas situaciones, pueden darse cuando los usuarios están atravesando congestión vehicular para llegar a algún destino, durante sus horas de sueño, entre otros. 
“Asu...(risas) creo que no podría apagarlo en horas de clase o trabajo...mmm...porque hay momentos en los que me aburro y lo saco para divertirme un poco (risas). ;Si en plena clase se me apaga, lo cargaría ahí mismo! (risas)...o sea, si sé que la clase va a durar mucho más... lo cargo, porque seguramente me voy a aburrir (risas). Pero, si veo que ya va a terminar lo cargo en mi casa, supongo (risas)."

"No lo apago, a menos de que se me esté acabando la batería y lo apague para ahorrar o cuando se cuelga. Aparte, si hay una emergencia o algo, no puedo estar incomunicada. (...) A veces cuando manejo lo veo, cuando paro el carro. Si no puedo contestarlo me quedo pensando quién será o que por favor toque luz roja para poder ver quién es (risas). De hecho es desesperante (risas)."

“ (...)Sí me levanto en la noche sea la hora que sea para responder; o sea, agarro y...por ejemplo, hoy me llegó un mensaje a las tres de la mañana, agarro y si puedo responder normal. (...) las clases me aburren, el trabajo me aburre y no sé, más divertido es estar con tu Smartphone."

"En realidad sí me levantaría en la madrugada porque si es a esa hora, yo particularmente lo relaciono con que es algo urgente, entonces yo sí me levantaría a ver el mensaje. Bien puede ser una llamada del trabajo o porque de repente le ha pasado algo a alguien o a un ser querido y quiero ver qué es, de qué se trata para estar tranquilo (...) igual por momentos lo cojo no...durante la clase, pero principalmente cuando hay breaks, prefiero aprovechar ese momento para coger mi celular y aprovechar al máximo ese poco tiempo y jugar....y ganar...siempre gano (risas).”

"En clase sí lo chequeo bastante (risas) eh...simplemente para ver si alguien me ha escrito, si me ha llegado algún correo. Si la clase está interesante y suena es como que digo: "quién me ha escrito" y si...sin que suene lo reviso es porque la clase esta aburrida (risas). (...) Podría apagarlo, sí. Lo he hecho alguna vez...no (risas), eh...porque siento que es como cortar comunicación con todo y no me gusta eso. Es más, no dejo que se apague (risas), o sea... siempre tengo un cargador en la cartera, lo pongo a cargar." 
Se encuentra también, que los usuarios de los dispositivos con internet presentan dependencia en lo que refiere a la rapidez de conexión que tiene el celular. Ello significa que todo aquello que realicen utilizando su Smartphone debe ejecutarse lo más pronto posible, ya que de esa rapidez con que envíen o reciban información diversa, depende su estado de ánimo momentáneo, sus decisiones y su proceder en muchos casos.

Sin embargo, dicha dependencia de la rapidez de conexión con diferentes cosas al mismo tiempo, podría ocasionar cierto retraso en el procesamiento de la información por parte de los usuarios, ya que no necesariamente todos los usuarios están preparados para recibir y ejecutar también, tal cantidad de información, siendo así que se presentan los malos entendidos por parte del receptor del mensaje o una interferencia en la comunicación o hasta desconcentración sobre un tema por darle mayor importancia a otro tema.

El hecho de tener mayor rapidez en la conexión del Smartphone les otorga a los usuarios una mayor cantidad de tareas a realizar al mismo tiempo, sean estas coordinaciones académicas o laborales, información que haya que transmitir o recibir, destinos a los que hay que llegar en el menor tiempo posible, conversaciones sociales y hasta revisión de algún tema de interés. Todo ello, con la finalidad de reducir el tiempo de espera o el tiempo que tomaría hacer cada tarea por separado, una a la vez.

"Tengo internet siempre, no demora en cargar y puedo hacer muchas cosas a la vez, eh...por ejemplo si tengo que mandar un correo de la chamba o bueno, responder un correo de la chamba (risas), eh...lo respondo al toque y aprovecho para responderle a mi amiga sobre cuándo juntarnos o sobre lo que me preguntó y a la vez aprovecho de...este...buscar a dónde voy a ir a comer con mi flaco hoy y...eh...de paso le respondo a la chica con la que hago trabajos en la universidad para juntarnos en su casa el sábado en la mañana (risas), o sea... hice todo eso en dos minutos."

“(...) cuando me han robado el celular, he estado dos semanas (risas) con un Smartphone antiguo, pero el internet era lento, o sea, sí tenía internet, si podía ver Facebook nada 
más...pero se demoraba horas de horas en cargar y es como que veía el relojito de arena cómo giraba y yo decía: "Ay cómo se demora esta porquería, que no sé qué” y es como que...me entraba la desesperación, porque era demasiado lento y eso también hace que esté de mal humor y que reniegue porque es como que...pierdes tiempo (risas). O sea, pierdes tiempo porque estás esperando a que cargue o a que responda el bendito celular y pucha...si fuera más rápido ya habrías respondido todo y habrías buscado lo que necesitabas al toque (risas)."

"O sea, sin el Smartphone no tienes esa posibilidad de ver, de terminar justo lo que te acaban de decir, de buscar justo lo que quieres buscar en ese momento y sacarte las dudas, eh...no lo tienes. Tienes que esperar a llegar a tu casa, y seguir con la pregunta a ver si es que se te ocurrió lo mismo, a ver si es que la encuentras, no sé... a mí me gustan las cosas como que súper rápido (...) mmm...te ahorran tiempo, puedes coordinar muchas cosas a la vez porque como son súper rápidos, o sea...aprietas algo y ya estás en lo que quieres buscar y puedes abrir varias cosas a la vez."

"Creo que han simplificado mucho el tema de la comunicación y el tema de la velocidad con la que compartimos información, lo cual es bravazo porque me pasaba de vueltas cuando la compu se demoraba o a veces el celular mismo cuando se demora, lo interesante... eh...es cuando puedes conectarte a todo a la vez y al toque, pero a la vez con una información que llega tan rápido...como que nosotros tampoco estamos tan preparados para eso; entonces, puede generar diferentes cosas como desconcentración, puede generar eh...que de repente te llegue tanta información que no puedas analizarla toda a la vez...entonces eh...puede jugar a favor o en contra..”

\section{Categoría: Sensación al separarse del teléfono}

En muchos casos ocurre que los usuarios del Smartphone olvidan este dispositivo en sus casas o en algún lugar en el que se encontraban. También, ocurre que se los roban de manera imprevista o simplemente los pierden o los dejan olvidados en algún lugar público y al regresar y preguntar por ellos, simplemente ya no están o nadie sabe darles razón alguna. 
Sea cual sea el caso, lo que se rescata de ello es que existe una respuesta emocional y/o racional por parte del usuario al separarse físicamente de su Smartphone.

Se observa que muchos usuarios al no estar físicamente con su dispositivo de un momento a otro, presentan un sentimiento de "soledad"; es decir, se sienten aislados respecto al entorno social. Ello se refiere a que el usuario, por el hecho de no poder enviarse mensajes, hablados o escritos, con sus amigos o familiares se siente solo, ya que no puede conectarse con nadie en todo momento como quizá antes lo hacía.

Sobre este tema, se puede observar un contrapunto interesante que fue referido por muchos usuarios del dispositivo con internet. El hecho de estar conectado con el Smartphone en todo momento del día, permite que aumenten las relaciones virtuales con otras personas; pero a la vez, disminuye las relaciones sociales físicas dentro del entorno cercano real. Ello quiere decir, que mientras que tal vez los usuarios se sienten "acompañados" al utilizar su Smartphone, dejan de participar del entorno físico inmediato en el cual están en ese momento, ya que dejan de observar a quienes están a su alrededor, a lo que ocurre cerca de ellos, a cualquier emergencia que pueda estar sucediendo que simplemente no la vieron por estar conectados en su celular.

"Sí, de hecho me sentiría sola...no podría hablar con nadie y estaría...sola (risas). O sea, no me imagino sin mi teléfono."

“Eh...creo que me sentiría aislado. Eh...un poco más sociable de repente, porque los Smartphones te aíslan mucho del mundo. Porque uno se sumerge en el celular para hablar con tus contactos, para estar pendiente de lo que pasa en las redes sociales o porque quieres ver un video o escuchar música. Puedes estar unido con tu familia y te aburres, coges el celular y puedes encontrar algo mucho más divertido, entonces te aíslas de las personas que tienes ahí físicamente, por ver lo que está pasando en tu Smartphone."

“Cómo sería... siento que me aislaría, me sentiría aislada de lo que sucede porque usualmente el contacto, y a sea para el trabajo, para contactar en la universidad con tus amigos, para estar informado de no sé, qué trabajos te dejan, qué tienes que hacer o en el 
tema social, con quién vas a salir, cómo reunirte, coordinaciones y todo pues (risas),

$$
\text { literal todo." }
$$

Otro sentimiento que se suele manifestar, no solo al estar separado el usuario del Smartphone, sino también al mostrarse el dispositivo lento en el procesamiento de la información o en la ejecución de diversas tareas, es el de la desesperación. Se puede ver cómo los usuarios sienten una fuerte desesperación e impaciencia ante tales situaciones.

En el caso de estar separados de su dispositivo, surge la desesperación en los usuarios al no poder enterarse de lo que ocurre en la vida de sus conocidos, al no poder estar al tanto de quién les está escribiendo o llamando; o el solo hecho de perder la oportunidad de estar comunicados con otras personas o disponibles en el caso de haber alguna emergencia o situación en la que otras personas requieran contactarse con ellos.

“Desesperada...o sea, porque no entraba rápido y a veces se colgaba e incluso nunca llegaba a entrar, había veces que se colgaba mi aparato, no me quería hacer caso...o sea...para ver lo que estaba haciendo todo el mundo...para chequear nada más...o sea...eh...Facebook y las noticias y qué hacen y todo (risas)'”

“Mmm...no pienso en eso básicamente, pero ahorita que me lo preguntas, definitivamente sería desesperante (risas). O sea ...no sabría cómo contactar a mis amigos o mis familiares porque solamente me sé el número de mi mamá o el de mis hermanas...de hecho, no podría hablar con ellas ni con nadie en verdad, qué horrible (risas)"

“si lo necesitara necesitara y no pudiera usarlo, ahí sí me...como que hasta me desesperaría porque si lo necesito...y y es una necesidad, entonces...no sabría cómo decírtelo. Mmm ...qué pasa si hay una emergencia y necesitan contactarse conmigo, no sé...mmm ... o yo con ellos, de todas maneras sería necesario tenerlo. Es más, te desesperas hasta cuando se te acaba la batería y pucha madre ...tienes que cargarlo" 
Así mismo, se encuentra que los usuarios del dispositivo con internet presentan un sentimiento de ansiedad al no tener su aparato consigo. Ello se debe a que sienten que están desconectados de lo que está sucediendo en las redes sociales y también desconectados de todas aquellas personas con las que suelen mantener alguna clase de comunicación, sea escrita o hablada. Es por ello, que se puede observar que los usuarios poseen un bajo control en cuanto al manejo de su curiosidad por revisar sus teléfonos.

“Mmm...en verdad dos veces me lo olvidé en mi casa y estuve sin el teléfono todo un día, las dos veces y no te voy a mentir que sentía la ansiedad por verlo (risas), o sea...quería ver Face y ver si me habían escrito así, pero conforme pasaron las horas, me acostumbraba un poco pero siempre te quedas pensando como que algo te falta."

“Cómo me sentiría... ansiosa. Porque es como parte de mí, es como una extensión de mi cuerpo y de mi entorno, entonces es...es él y yo. O sea, quiero saber de mis amigos, mi mamá, no sé. Creo que es cuestión de...bueno me lo han robado hace poco y fue feo y a los dos días me compré un nuevo equipo."

“(...) y de hecho sería una situación incómoda...mmm...recontra angustiante de hecho porque me pondría ansioso creo (risas). No me gustaría estar sin mi cel, es que ahora es imposible estar sin él porque todo lo que buscas está ahí y aparte tienes el número de todos ahí, de hecho ya nadie se memoriza el número de nadie (risas)."

“De repente porque... bueno no sé, si lo uso como excusa, de repente me pueden estar escribiendo por algo importante o me pueden estar llamando y...igual tengo que estar pendiente por si acaso. De repente...o me pica más la curiosidad por prender,a ver qué pasó en el Facebook o si me están escribiendo en el Whatsapp."

Se denota un alto grado de frustración por parte de los usuarios del Smartphone cuando se encuentran en una situación en la que éste dispositivo está ausente, ya que se ven imposibilitados de comunicarse con quien usualmente lo hacen, de buscar información que 
necesitan en ese momento o de simplemente pensar en que deberán esperar más tiempo para obtener alguna respuesta o enviar alguna clase de información en ese instante.

“(...) y cuando me ha pasado me frustré horrible (risas), es que no puedo hacer nada pues, no puedo hablar con nadie ni saber nada tampoco (risas)."

"O sea, como que un poco frustrada porque como que...tengo que estar totalmente en contacto, sí...como que me frustraría "Y ahora cómo lo hago" porque normalmente todo lo haces por el Smartphone, pero sí...me sentiría un poco frustrada porque no me puedo comunicar. Frustrada (risas). Como que... a veces tú, o sea cada vez yo siento que la nueva sociedad, especialmente nosotros queremos las cosas para ayer, entonces...tú quieres hacer las cosas rápido y sin eso, que justo es la herramienta que te da esa rapidez y no la tienes."

“Creo que probablemente sería frustración, por intentar tener... o sea, toda la información y a la velocidad a la que me llegaba. Es como cuando se malogra te sientes un poquito frustrado al comienzo y luego se te va pasando...pero después de bastante tiempo, qué feo."

Un sentimiento bastante común en los usuarios del Smartphone al encontrarse separados de éste es el de ausencia, es decir que suelen presentar una sensación como si algo les faltase, como si se hubiesen acostumbrado a que éste aparato sea un accesorio que va junto con su vestimenta en el día a día. Así mismo, se muestra un sentimiento de vacío y una fuerte necesidad de tenerlo en sus manos o a su alcance cada vez que se les antoje, lo cual algunos llaman dependencia. Ello, debido, muchas veces, a que además de utilizarlo cuando realmente lo necesitan (sea para comunicarse o ara el envío de archivos o información), lo utilizan en momentos de ocio o cuando se encuentran aburridos.

"Mmm...me sentiría como que me falta...este...sí pues, sentiría que me falta porque ahora cuando tienes momentos en los que no haces nada, tu fiel compañero es tu cel (risas)." 
“y que estemos separados mucho tiempo es como que hay un vacio...de hecho, sí he sentido como que algo me falta porque es algo que usualmente tengo siempre conmigo, es mi bebé (risas)."

"O sea, es extraño porque de hecho sientes como ya una necesidad y una cierta dependencia hacia el teléfono...eh ...como que algo te falta. Lo que pasa es que...eh...creo que ahora para todos el cel es un accesorio más (risas); o sea, ya nadie sale a la calle sin su celular porque además de usarlo cuando lo necesitas, lo usas cuando no tienes nada que hacer o estás esperando en alguna cola o en los tiempos libres que tienes en la chamba o en los huecos que tienes en la $u$."

Se evidencia que los usuarios del dispositivo con internet sienten estrés al no tenerlo consigo mismos, ya que ello les imposibilita realizar todas las tareas que suelen ejecutar en dicho aparato. Así mismo, enlentece el ritmo que llevan al usarlo para asuntos laborales o académicos, ya que de no tenerlo en el momento en que lo necesitan o requieren utilizarlo, deben esperar llegar a sus casas o a algún lugar en el que puedan utilizar una computadora o un dispositivo con internet.

Sin embargo, se encuentra cierta contradicción respecto al estrés en sí mismo, ya que si bien, como se mencionó en el párrafo anterior, hay un sentimiento de estrés al no tener el celular consigo; existe también un sentimiento de liberación de estrés justamente al no tenerlo. Ello se debe a que esta sensación de estrés únicamente aparece en relación a temas laborales y académicos, puesto que solo en estas dos áreas los usuarios sienten el estrés directamente, que implica el hecho de no poder desconectarse de sus responsabilidades; esto es, el no poder dejarlas en una universidad o en una oficina de trabajo, porque simplemente continúan con el dispositivo conectados a todo aquello que, así como los conecta con lo social y el entretenimiento, los mantiene conectados también a todas sus responsabilidades y deberes.

Por ende, muchos usuarios se sienten estresados al no tener su Smartphone a la mano porque saben que el trabajo y la universidad y las coordinaciones de estos dos siguen 
dándose, pese a que ellos no puedan verlas en el momento en que se den. Así también, se podrían sentir librados de este estrés al no tener su dispositivo consigo en un determinado momento.

“Bueno, sin el Smartphone... antes justo me lo había preguntado y capaz me estresaría un poco porque en cierta forma es algo que facilita y de hecho agiliza mi vida en todo sentido. O sea, me ayuda en la universidad porque mando correos o hago trabajos o busco info o lo que sea de la u. Más, también me sirve para cosas del trabajo porque puedo coordinar con mis compañeros de trabajo o enviar o recibir información, etc."

“Mucho más lenta, menos estresada o no sé si más estresada. Es que, o sea, menos estresada por el hecho de no estar todo el rato, o sea viendo y prendiendo el celular a ver si es que hay algo o...más estresada porque sé que al día siguiente voy a llegar y voy a tener una ruma de cosas enorme para hacer porque no me dijeron como que el día anterior para ir avanzando, tanto en la chamba como en la universidad."

"Mmm...directamente estresado. Porque me parece que lo que nos da los Smartphones y la velocidad de la información es un exceso de control sobre muchas tareas a la vez. Lo que pasa también...es que...creo que estoy acostumbrado a tener el control y el feedback de todas las cosas que estoy haciendo. O sea, necesito retroalimentación al tiempo que está...que está sucediendo algo; ya sea un trabajo en grupo, ya sea un proyecto que se está armando, ya sea algún proceso, entonces el no tenerlo me generaría cierto estrés de no saber qué cosas están pasando en ese momento."

\section{Categoría: Relación con el interlocutor}

Se ha descubierto que un primer tipo de relación que los usuarios mantienen con los diferentes interlocutores es fácil. De allí, que los entrevistados consideran que es más fácil comunicar cosas que quizá no se atreven en persona; tales como: expresión de sentimientos amorosos hacia otra persona, coqueteos, o incluso comunicados que requieran una respuesta 
ante una excusa o petición, la cual no será posiblemente del agrado de los mencionados usuarios o sea negativa en todo caso.

Además, les permite organizar de una mejor manera las ideas que quieren expresar a otra persona en una mayor cantidad de tiempo, en la cual pueden pensar sobre la estructura de aquello que comunicarán o incluso revisar lo que escribieron o grabaron, antes de enviarlo al interlocutor. Esto le brinda mayor confianza y seguridad al usuario, ya que cobra valor para escribir o preparar aquello que va a comunicar y una vez que esté completo podrá ser enviado a través de una pantalla, sin tener que recibir una respuesta inmediata verbal y no verbal.

"No, pero de hecho es más fácil hablar por el Smartphone que en persona porque a veces hay cosas que son difíciles de decir en persona y de hecho es más fácil cuando tienes una pantalla al frente, porque no te ven (risas). O sea; ponte, cuando me mecho con mi flaco, prefiero explicarle por ahí y ya cuando dije todo, ya normal podemos hablar en persona (risas)."

"porque; o sea, yo no soy tanto de hablar verbalmente; o sea, también a mí me encanta escribir; o sea, más me gusta la comunicación escrita que la comunicación oral y a mí se me hace más fácil escribir lo que está en mi mente, ponerlo por escrito, no sé es un medio de expresión para mi...Sí, es como que te hace más valiente, como que puedes expresarte de mejor manera, para mí, bueno...para mí. O sea, no tienes que pensarla tanto, o sea para mi hablar, requiere pensamiento, o sea tienes que pensar lo que vas a decir...sólo por eso...no por roches o algo...es más que nada porque yo a veces tartamudeo cuando hablo y a veces me olvido de lo que voy a decir en la oración (risas)."

“O sea, básicamente cuando vas a coquetear, no sé, es más fácil decirlo por escrito que decirlo en persona...creo. Ponte, cuando salía con mi flaco, antes de que sea mi flaco, a veces le decía las cosas más por escrito, por Whatsapp y en persona nunca le decía nada porque me siento más segura ahí, o sea siento que puedo pensar más las cosas y escribirlas, en vez de decirlas nada más. Como que, puedo pensar bien lo que voy a 
escribir y me tomo el tiempo que quiero, en cambio cuando hablas con una persona no vas a estar ahi callado pensando que vas a decir (risas), me da seguridad."

"Por Smartphone en vez de en persona ...mmm ... asu...no sé, declaraciones de amor..."

"Por ejemplo, eso no es tanto de la universidad sino del trabajo. Tengo un viaje programado, mi familia compró unos pasajes sin consultar, que coinciden justamente con los días de trabajo, entonces obvio me da un poco de rochesito decirle a mi jefa, ya le había dicho vacaciones para octubre, pero eso no lo esperaba, como no me consultaron, entonces dije "ya, voy a tener que adelantar en julio, cómo le digo a mi jefa”, si ahorita estamos con mil cosas y no hay ni tiempo para hablar de esto. Entonces creo que por whatsapp es como que ...más suave."

“Bueno, por ejemplo la semana pasada, este...cancelé un cliente. O sea, como que corté la relación con ese cliente porque el cliente generaba problemas y nos demandaba más tiempo del que tenía destinado para esa cuenta y había una desorganización que no venía de nosotros. Entonces, simplemente por un tema de cortarlo de inmediato...o sea, lo lógico hubiera sido acercarme y cortar la relación con la persona; o sea, decirle que ya no íbamos a trabajar con ellos y ya. Pero me parece que fue una salida mucho más rápida y mucho menos vergonzosa y mucho menos tramitosa porque por teléfono de ley se puso como una fiera y me imagino en la vida real esa reacción."

Un segundo tipo de relación entre los usuarios y los interlocutores (receptores) es la indiferente. Este tipo de relación se da cuando los usuarios no presentan ni facilidad, ni dificultad alguna para comunicarse a través del Smartphone. Es decir, que no existe mucha diferencia entre el hecho de comunicar algo a través de dispositivo o en persona, ya que podrían dar el mismo comunicado por cualquiera de los dos medios, siendo a veces que prefieren comunicarse personalmente; puesto que de este modo, pueden ver a sus conocidos y también pueden comunicar cualquier tipo de tema incómodo o difícil de conversar por otro medio que no sea el personal, entre otros. 
“Eh...este...ya, lo que pasa es que puedo decir algo que seguro me va a costar decirlo en persona por el cel porque me van a gritar o significa mecha segura o me da roche decirlo en persona, no sé. Pero, el tema es que ...este...también creo que me tragaría mi roche o me orgullo un toque para ver qué onda, qué me dice a la cara. Así que, las dos formas tengo para decir lo mismo."

"Normalmente me gusta decir las cosas en persona, aparte, es más divertido ver a tus amigos, ¿no? (risas), pero no tengo problema con decir algo que me molestó o algún tema que me va a llevar a discutir, por teléfono. De hecho, puede ser cualquiera de las dos formas, por el cel o en persona, pero al final digo lo que quiero decir igual (risas)"

\section{Categoría: Interferencia}

Actualmente, los estudiantes, y usuarios del Smartphone a la vez, están presentando una contradicción en su percepción sobre el impacto que tiene en sus vidas el uso del dispositivo en el área académica. Esta contraposición se debe a que en ciertas ocasiones perciben que este dispositivo les brinda beneficios en esta área ofreciéndoles información en cuanto la necesitan, agilizando sus trabajos y coordinaciones universitarias, y brindando las herramientas necesarias para su estudio.

Sin embargo, piensan que en muchas otras ocasiones el dispositivo interfiere con este espacio académico que tienen. Ello se debe a que en el momento en que deciden estudiar uno o más cursos, hacer algún trabajo o prestar atención a las explicaciones de los profesores en sus clases; tienden a distraerse con su Smartphone, sea porque recibieron alguna notificación o información, o porque sienten esta necesidad de revisarlo para ver si tienen algún tipo de mensaje o para revisar el Facebook o simplemente algún otro tema de interés. Es allí donde pierden más tiempo del que pensaron inicialmente que sería un simple chequeo esporádico;

por ende, aquella tarea o momento en la clase en que debe prestar atención o tiempo de estudio que debería tomarles un cierto tiempo para culminar, les suele tomar la mitad del tiempo más, aproximadamente. 
"Sí, sí lo uso pero no es constante es por momentos más que nada ...y sí, mientras estudio lo chequeo o respondo mensajes siempre, o sea...de vez en cuando, pero puedo estudiar y verlo a la vez...creo (risas). Mmm...si estudio 3 horas, estaré respondiendo al whatsapp de vez en cuando...mmm ...de hecho durante las tres horas, pero por ratitos, no las tres horas completas, será tipo...una hora y 20 o como una hora y media maaaaximo. Siento que a veces me ayuda y a veces me perjudica. Porque me ayuda comunicándome con gente de mi clase pero me distrae en clase. Me distrae en clase porque puedo estar en Facebook o viendo cosas en internet, no sé, tipo: vestidos, zapatos, perfumes, cualquier cosa o simplemente puedo estar hablando con mi enamorado o con otras amigas..”

"De hecho me han llamado la atención por usar mi Smartphone, sí, pero no muchas veces. Pucha, estaba discutiendo por whatsapp con mi enamorado y jno podía dejar de ver el celular por eso! Entonces, la profe dijo que guarde el celular y yo no escuché y se acercó a mí y me dijo que lo guarde o me lo quitaba, así que lo dejé, pero cada vez que se volteaba lo miraba y respondía lo que podía (risas)."

"No, definitivamente no, la creo mala porque debería estar concentrándome en mi trabajo o en los estudios. Interfiere obviamente, porque; o sea, no me deja estudiar (...) De todas maneras, sí creo que pierdo mucho tiempo...o sea, si no tuviéramos todas esas maravillosas aplicaciones, no estaría tanto tiempo, seguro. Es más, varias veces, me pasa un montón ...por ejemplo...cuando no tengo internet y me estoy colgando del wifi de mi casa y como mi trayecto de mi casa a la universidad es como una hora, como que estoy en una conversación súper intensa por whatsapp o no sé, es como que no puedo dejarla, es como que tengo que...como que, terminar de responder y ahí recién irme."

"En la u, cuando veo que no estoy entendiendo o que ya estoy muy distraída, dejo un toque, y ya...presto atención y de nuevo cuando ya entendí, vuelvo a usar el celular (...) Si no tuviese Smartphone, estudiaría mucho más rápido (risas) como que la mitad de lo que me demoro. Por ejemplo si un día tengo examen puedo estudiar unas dos horas o tres máximo y estoy con el celular el doble, así. O sea, más paso en el celular que 
estudiando...no sé, llega un sonido o algo, a veces ni siquiera me llega nada y simplemente lo agarro para ver Facebook (...) en la clase sólo me distraigo un minuto y cuando me doy vuelta ya avanzaron un montón. Podría rendir mejor sin el Smartphone porque no me distraería. Cuando me robaron y dejé de tener Smartphone."

“O sea, puede ser que de repente tengo alguna consulta a un amigo mío o un compañero que está llevando el mismo curso, entonces le pregunto si tiene esa información o si me puede ayudar con algo, de hecho es más rápido escribirle a estar llamando y todo. $O$ te pueden pasar archivos también por ahí o una foto. Pero también, reviso Facebook, un rato de distracción también, porque estar metido 4 horas estudiando, de hecho también te sirve un momento de distracción y que te ayuda a despejar tu mente un poco. Mmm...siento que te ayuda para ciertas cosas, pero si es que abusas del uso del celular, de hecho te podría generar."

"Sí, sí... a veces digo "Esta separata la tengo que terminar en una hora a lo mucho porque tiene cinco hojas, con diez leídas", pero no, esa hora se transforma en tres porque dos cojo el celular, me distraigo mucho. Se prolonga mucho el tiempo que debería dedicarle a estudiar gracias al celular que me distrae, que prolonga que termine cosas importantes. Creo que la cantidad...iría casi en la misma cantidad (risas), creo que más estoy en el celular que estudiando (risas), porque a lo mucho le dedicaré dos horas al estudio de repente. (...) en momentos en que estoy en clase o estudiando me distrae, porque quiero ver qué está pasando en mi red social o de repente quiero conversar con alguien por Whatsapp o se me vino una canción o un video a la mente de la nada y me distraigo y entro a Youtube para ver esos videos."

“Es básicamente distracción, interfiere mucho con mi vida en la u. Sí, pierdo mucho tiempo...pierdo muиucho tiempo (risas), tiempo que he podido designar a leer una separata para un examen que pueda haber al día siguiente y bueno... uso el celular para conversar en Whatsapp o entro al Facebook, lo que sea...me distrae mucho el celular, estoy meditando mucho con tu entrevista, me has hecho pensar. (...) sí, no me queda otra 
más que preguntarle al compañero de al lado y él me dice yo también estaba con mi Smartphone”, y nunca me enteré qué pasó."

"Sí...fijo pierdo mucho tiempo porque ay me distraigo con facilidad (risas), no pero en el aspecto académico quizás un poco más, sí, y dependiendo del profesor entraba o no a la clase...porque pucha este...tenía clase a las siete de la mañana, me levanté a las seis, pudiendo tener tiempo de bañarme, cambiarme e ir, pero pucha no sé...empecé a ver las notificaciones de la mañana y ya pues. (...) No, no nada...aunque cuando estaba con flaco y nos mechábamos por Whatsapp, no entraba a clase. Me quedaba mechándome (risas)."

“Lamentablemente sí. Sí, y me distrae un culo! (risas). Para mí el Smartphone es lo peor que puedes hacer para tu vida académica. Simplemente te distrae y no te deja estar en tus cinco sentidos ahí porque estás pendiente (...) Porque seguro que me han escrito, simplemente no lo veo... o sea, estoy pensando que está ahí. Si estudias dos horas, o sea, algo de unas tres horas y media... lo podrías hacer en dos. Dijiste "no, solamente un minuto, me voy a relajar un minuto, no solamente voy a ver esto”, contestaste lo que...o sea, si ibas a contestar una sola cosa contestaste 50 y si ibas a abrir una sola cosa abriste 50 y los 10 minutos que ibas a usar, se convirtió en 40 minutos.",

“Ahí viene un tema de responsabilidad. O sea, si tú estudias antes...o sea, si eres responsable con tus estudios no creo que haya ninguna diferencia. Pero sí...de hecho sí afecta y te ayuda a mejorar tus notas porque te permite disponibilidad de información en un momento dado. Estás en la mitad de la universidad, no tienes internet y no tienes libros. Muy bien, tengo un libro en mi Smartphone; o sea que sí ayuda.”

"Más que todo es el Whatsapp, entonces por eso cuando realmente me quiero concentrar, lo pongo en silencio y le quito el vibrador y lo alejo (risas) o en caso extremo...y y lo apago. Yo creo que sí recortara todos los tiempos en los cuales agarro el teléfono me demoraría muchísimo menos de lo que me demoro estudiando (...) Mmm...creo que finalmente sí me ayuda porque mucha información nosotros nos la pasamos por el teléfono y en la universidad siempre estamos pendientes de qué se ha dicho en el grupo, qué se ha 
colgado, qué separatas se han puesto, qué avisos nos ha dado el profesor. Ahora, de hecho que sí hay una parte negativa que es la distracción que puede generarte."

“Yo creo que sí me ayuda. O sea, en tener la información súper al instante, en poder coordinar con la gente, yo creo que ayuda bastante en eso $O$ sea, me ayuda un montón, me ayuda en obtener información para mi desarrollo como profesional, o sea de hecho sí me...me cuesta un poquito el que se prenda una alerta y de hecho me desconcentra y a veces te puedes perder un toque lo de la clase y obvio ahí cuando te pregunta el profesor estas como que...bueeeno (risas)."

Los usuarios del Smartphone encuentran una dicotomía en cuanto al uso de este dispositivo en el ámbito laboral. Ello debido a que; por un lado, los beneficia brindándoles diversas herramientas, información y diferentes funciones que permiten la agilización y efectividad de sus tareas laborales; así como, les permite la realización de coordinaciones organizacionales.

No obstante, por otro lado encuentran que el dispositivo con internet ocasiona interferencia al momento de ejecutar parte de sus labores; ya que, suelen distraerse al momento de recibir alguna notificación o información o correo, o simplemente se distraen realizando chequeos esporádicos para revisar las noticias sobre sus conocidos o alguna aplicación de interés.

“No, en el trabajo también...o sea, cuando estoy mucho rato con el celular y me doy cuenta que tengo que trabajar (risas), lo dejo. Es más...mmm, me pasa más en el trabajo que en la universidad (risas)...pero es porque a veces no me dejan trabajo, entonces $o$ estudio o estoy con el celular. O sea, podría acabar más rápido en el trabajo si no usara mi celular. $O$ sea, a veces tengo un montón de tiempo libre en verdad y estoy con el celular, pero cuando hay trabajo también estoy con el "cel” y me distraigo. (...) Más que nada en el trabajo. Me ha demorado un día... algo que podía hacerlo en dos horas."

“Entonces, todo el tiempo que estoy trabajando estoy a la vez viendo archivos, documentos, correos, buscando videos, y a la vez editando, diseñando y todo. Sobre lo 
social en realidad me distrae poco porque hace meses me he metido un poco más en el trabajo, pero de hecho es una distracción; o sea, sí te retrasa un poco lo que quizá pudiste terminar antes."

"Pucha ...en verdad...así como me distrae en la parte de estudios, me distrae en el trabajo. O sea, el tema es que me quedo revisándolo cuando acabo algo en mi chamba y luego veo y tengo mil correos y estoy corriendo como loca para poder terminar antes de la hora de salida... y...al final me voy tarde por haber estado viendo el cel todo ese tiempo (risas), pero fijo fijo me ayuda en varias cosas, sobre todo para coordinar con la gente de la chamba o cuando me fui y les digo dónde está lo que buscan o cuando estamos en reu y estoy buscando algo sobre lo que hablan."

\section{Categoría: Rendimiento Académico}

Se ha encontrado que los usuarios del dispositivo con internet, poseen dos percepciones opuestas sobre la influencia de éste en su rendimiento académico. Estas son, por un lado la percepción de que el Smartphone ayuda al usuario a mejorar su rendimiento académico, debido a las herramientas y funciones que le brinda.

La otra percepción encontrada es que contrariamente, los perjudica, ya que interfiere con sus estudios y tareas académicas, al llegarles notificaciones o porque simplemente ellos deciden revisar su dispositivo cada cierto tiempo y se mantienen conectados más tiempo del que inicialmente tenían planeado.

"De hecho tendría un mejor rendimiento porque ya no tendría con qué distraerme. Serían menos las posibilidades de distraerme."

"No, yo sé que sin el cel, estoy cien por ciento seguro que podría rendir mucho más, todo elemento distractor te perjudica." 
"Estoy bien creo. No sabría decirte si es por el Smartphone, pero de hecho es útil poder bajarte las diapositivas o la bibliografía en tu tiempo libre mientras viajas, porque con el tráfico, una hora, se hace medio aburrido, entonces reviso ahí y puedo estudiar de ahí y encontrar la info que necesite también."

"Es un poco dificil pensar... o sea, si es por la parte de concentración en verdad como te digo es algo de voluntad; o sea, ya tú decides si dejarlo a un lado o quedarte pegada en la pantalla, pero yo creo que, o sea...me iría mejor con el Smartphone porque tengo la información, pero si es por parte de que si es un elemento para distraerme, sí me iría peor...entonces estoy en una controversia. O sea, yo creo que con Smartphone si me va mejor porque tengo todo a la mano, entonces hago mis cosas al toque. Por ejemplo, tengo lo de Google notes, y apunto cosas ahí y sí me sirve como una herramienta plus, pero peor por el hecho de que es un distractor."

En cuanto al promedio académico de los estudiantes universitarios que utilizan Smartphone, se puede observar que la relación entre éste y la utilización e influencia del dispositivo es nula. De allí, que los usuarios no encuentran relación entre ambos factores; pese a que interfiere en gran medida en sus estudios y realización de diversas tareas universitarias.

Esto significa que el promedio académico es independiente de la influencia que el Smartphone ocasione sobre los usuarios. Se ve que el uso del dispositivo no influye en el promedio en sí, sino en el tiempo que emplean al realizar diversas cosas relacionadas con el ámbito académico; sean trabajos o estudios u otras tareas relacionadas con la universidad.

"Se ha mantenido...siempre he sido media...normal. O sea, el cel no tiene nada que ver porque de hecho sí, me desconcentra cuando estudio y me toma más tiempo todo por el bendito celular (risas), pero mi promedio no ha variado por él." 
"Desde que empecé la universidad usaba el celular, entonces siempre he tenido celular, pero igual mi promedio ha subido. Mmm...creo que el que me distraiga o me desconcentre cuando estoy estudiando o haciendo trabajos sola o en grupo...eh ...como que no afecta tanto mis notas sino más mi concentración."

"Creo que se ha mantenido pero ha sido quizá porque he tenido que aumentar las horas de estudio de las que he tenido planeadas inicialmente, O sea quizá, si no lo tuviese...si no tuviese el teléfono mi promedio se mantendría...o sea, seguiría siendo el mismo pero no sería 3 horas de estudio sino quizá una hora y media. Entonces, le he tenido que poner más tiempo por el tema del celular pues no. Porque me distraigo, entonces si tengo planeado leer algo y aprendérmelo bien para llegar a ese mismo nivel tengo que emplear mucho más tiempo del que originalmente podría ser si no me estuviese distrayendo tan seguido. Pero el punto es que mi promedio no se afecta por el celular."

\section{Categoría: Temática a través del Smartphone}

Uno de los temas de conversación que se da a través del Smartphone que genera mucha controversia es de índole personal. Es decir, los usuarios suelen conversar de temas que quizá sean delicados o que provoquen alguna reacción negativa o incomodidad por parte del interlocutor (receptor) y de quien envía el mensaje.

Así mismo, suele ser el dispositivo en muchas ocasiones, el medio de preferencia para expresar sentimientos afectivos o para discutir sobre asuntos que puedan generar una especie de debate al conversarse personalmente; lo cual se suele dar de acuerdo a la urgencia del tema percibida por cualquiera de los usuarios.

Del mismo modo, se puede observar que a muchos usuarios les facilita el hecho de pedir opiniones sobre algún tema específico que desean preguntar, para conocer otros puntos de vista distintos al de uno mismo. 
"No sé....tipo...sentimientos, o cuando estoy molesta por algo o cuando tengo que decir "sorry"...no sé, ese tipo de cosas más personales fácil (risas). Es que, es súper incómodo decir sorry, es como que...no sabes qué hacer en ese momento (risas). O sea, dices sorry y luego...esteee...nada (risas)."

"Coqueteo más que todo...coqueteo, me atrevo más porque no tengo a la persona ahí, que me mire o me haga sentir incómodo, así que me lanzo con todo. Creo que es fuertaso cuando quieres decirle no sé, lo que sientes a alguien y da roche pues porque qué pasa si no le pasa lo mismo o qué pasa si no está en tu misma frecuencia... ya pasaste el roche de la vida. En cambio con el cel, pasa más caleta pues porque si no se da, ya queda ahí y cambias de tema nomás."

"Creo que más que nada, temas delicados, eh...o sea, que pueden generar en la otra persona una mala reacción o que te grite o que no le parezca lo que le dices. Igual, depende de la persona y del tema. Si son mis amigas o mi familia o mi enamorado, normal decirlo en persona, pero muchas veces sí prefiero decirles por whatsapp. Igual, puedo decirlo en persona, pero creo que prefiero decirles por el cel este tipo de cosas."

"No. Pero sí pregunto por consejo, o pido opiniones para darme más como un inside y outside. Puedes ver bien el tema desde otra perspectiva y puedes analizarlo, algo que tal vez no hayas visto, eso es lo que me gusta acerca de pedir opiniones. Es la forma más fácil de poder ver un problema desde otro punto de vista que tal vez en mi perspectiva, agobiado por el mismo, no puedo."

Por otro lado, existe otro tipo de temática que se suele tratar a través del Smartphone, que es la cotidiana. Ello quiere decir que los usuarios suelen conversar sobre temas quizá un poco más banales o triviales; tales como, eventos o coordinaciones puntuales o preguntas específicas que requieran respuestas cerradas. Así también conversan sobre temas que no generen un cambio drástico en la actitud o el humor del interlocutor; es decir, que no genere un impacto negativo en él. 
Ello, se puede ver sostenido desde el hecho de que al tratar temas más personales por medio del Smartphone, en realidad se pierde más tiempo de lo que quizá podría demorar conversarlo en persona, ya que se presta a muchos malos entendidos, porque justamente son textos sin entonación, ni lenguaje no verbal; los cuales facilitan la intencionalidad y motivo de dichas conversaciones sobre temas personales.

“Mmm...no hay cosas específicas que diga a través de los Smartphone creo...o sea, hablo de cualquier cosa que no sea muy seria o personal porque si no, ya lo diría en persona. No soy de las personas que publican todo lo que hacen en el día, o cómo me siento o de estarlo hablando por el teléfono. Lo máximo que hago es colgar alguna foto, pero nunca pongo status, no va conmigo...o sea, jamás publico lo que pienso...este...ni pido opiniones por ese medio tampoco..."

"Sí, antes más creo, pero sí. O sea, a veces hablo con mis amigas en la clase, más que nada, rajes o hablar de alguien porque como no lo puedes hablar en persona ahí mismo, entonces comienzas a burlarte por ahí de gente de la misma clase o cosas del salón pues (risas), pero de hecho son cosas que no interesan, no pasa a mayores."

"De repente si son eventos por ejemplo, a veces crean eventos en Facebook y solo pones asistiré y no tienes...es más, en esos casos es mejor solo poner un asistiré y ya no tienes que estar llamando o yendo en persona a ver si van o no al evento, es muchísimo más rápido, pero si son cosas más privadas o más importantes, creo que mejor es directamente porque pucha...es una vaina cuando dices cosas así personales o íntimas o de problemas o de cómo te sentiste con esto que pasó, porque al final se malentiende todo y como no pueden ver tu cara ni cómo lo estás diciendo."

"O sea, en verdad las cosas que más escribo por el cel son tipo: "A qué hora vas a llegar", “Me puedes por favor mandar esto”, cosas como que recontra precisas que no es necesario una llamada o estar face to face y son entendidas con tres palabras o necesitan una respuesta puntual o única o tipo un sí o un no, manyas. O sea, cosas más de coordinar o pedir favores puntuales o responderlos también." 


\section{CONCLUSIONES}

- Mientras que el uso del Smartphone no afecta el promedio académico para los estudiantes, sí afecta el tiempo que se dedica a las actividades académicas.

- Genera ahorro de tiempo en cuanto a la búsqueda de información y coordinaciones académicas.

- Existe una necesidad del usuario de estar constantemente conectado en el celular para sentirse comunicados como para evitar el aburrimiento o tiempo de ocio.

- Existe una necesidad del usuario de realizar constantes revisiones rápidas sin razón de llamada o mensaje.

- El pensar que no lo pudieran tener consigo, acarrea sentimientos negativos o desagradables.

- Los usuarios prefieren utilizar el Smartphone como medio de comunicación para temas que generen una respuesta negativa o incómoda de parte del interlocutor, ya que ello les permite esconderse detrás de una pantalla.

- Mientras que el Smartphone les permite realizar funciones que les ayuda en el ámbito académico, a la vez interfiere con su concentración en el estudio.

- Los usuarios perciben que el uso del Smartphone es beneficioso al brindarles herramientas e información rápidamente; pero es perjudicial al realizar actividades universitarias que requieran concentración 


\section{RECOMENDACIONES}

- Lograr una atención sostenida de mayor duración, manteniendo el celular guardado y en silencio al momento de estudiar o hacer trabajos académicos y no revisarlo hasta finalizar lo que se está realizando.

- Mantener el sentido de la comunicación personal social física; para así, desarrollar mayor habilidad comunicacional en diferentes contextos sociales.

- Desarrollar una mayor atención hacia el entorno físico inmediato en esos momentos de aburrimiento u ocio; ya que, podrían evitarse accidentes o ser víctimas de robo, asimismo se podría brindar ayuda a alguien que lo necesite en ese momento.

- Contar con estrategias alternativas, de modo que si olvidan el celular o lo pierden, se tenga acceso a los números telefónicos e información más importante que permita mantener la calma y proponer soluciones eficaces en dichas situaciones.

- Promover un mayor desarrollo de la habilidad comunicacional y escucha activa mediante el establecimiento de conversaciones personalmente sobre temas delicados o personales, en vez de utilizar el Smartphone como medio para esto; evitando así, malos entendidos y a la vez.

- Comunicarse a través de una llamada telefónica o personalmente con aquellas personas cercanas de quienes se desee saber cómo están o cómo les fue con algún tema específico, en vez de hacerlo por escrito y despersonalizado.

- Complementar la investigación, explorando cuantitativamente la influencia del uso del Smartphone en diferentes áreas como: familiar, social, afectiva, entre otras.

- Realizar y validar un cuestionario para obtener información sobre la influencia del uso del Smartphone sobre algún área específica. 


\section{REFERENCIAS}

ABC. (06 de noviembre del 2011). La nomofobia o el miedo irracional a salir a la calle sin el teléfono. Recuperado de: http://www.abc.es/20110906/sociedad/abci-nomofobiaenfermedad-movil-201109061728.html

Arroyo, M.M., y Merlino, A. (2009). Investigación Cualitativa en Ciencias Sociales. ( $1^{\mathrm{a}}$ ed). Buenos Aires: Cengage Learning.

Bedoya, Perez Granda y Jiménez. (24 de abril del 2013). ¿Se constituye el uso del Smartphone en una adicción? Recuperado de: http://bibliotecadigital.usbcali.edu.co/jspui/handle/10819/1306

Castro, S. (2012). Ubicuidad y comunicación: los smartphones. Revista Casqui Revista Latinoamericana de comunicación, (118), 91 - 95.

Cruz, E. (2012). La era de los smartphones. Revista Bussines negocios en el Perú, (206), 30 -34 .

Definición de Internet. Recuperado de: http://definicion.de/internet/

El Observador. (26 de julio del 2011). Smartphones, la adicción que preocupa a los psicólogos. Recuperado de: http://www.elobservador.com.uy/noticia/206182/smartphones-la-adiccion-quepreocupa-a-los-psicologos/

Fernández, M. (1990). Factores de Personalidad y Rendimiento Académico: Un estudio comparativo. Revista Cuestiones de psicología del aprendizaje. (1), 130 - 133.

Grimaldos, L. (7 de noviembre del 2012). Impacto de los teléfonos inteligentes en la sociedad actual. Recuperado de: http://impactodelossmartphonesenlasociedad.blogspot.pe/

Hernández, R., Fernández, C. y Baptista P. (2014). Metodología de la investigación (6ta ed). México DF: McGraw-Hill.

Información e investigación. (05 de noviembre del 2011). Los jóvenes y los Smartphones. Recuperado de: http://barrio.universia.cl/tiempo-libre/2011/09/05/159976/losjovenes-y-los-smartphones/

Katamaya, R. (2014). Introducción a la investigación cualitativa: Fundamentos, métodos, estrategias y técnicas. Lima: Fondo Editorial de U. Inca Garcilaso de la Vega. 
Lejoyeux, M. y Ades, J. (2003). Las nuevas adicciones: Internet, sexo, juego, deporte, compras, trabajo, dinero. Barcelona: Kairos.

Jiménez-Murcia, S. y Ferré Martí, J.M. (2015). Adicción a las nuevas tecnologías. Madrid: Siglantana.

Quiroz, M. (2001). Aprendiendo en la era digital. Lima: Fondo de Desarrollo Editorial Universidad de Lima.

Ron, R., Álvarez, A. y Núñez, P. (2013). Smartphones y Tablets ¿Enseñan o distraen? Madrid: ESIC.

RT. (7 de agosto del 2011). Smartphones, la nueva adicción del siglo XXI. Recuperado de: https://actualidad.rt.com/sociedad/view/31004-Smartphone\%2C-nuevaadicci\%C3\%B3n-del-siglo-XXI

Schmidt, E. y Cohen, J. (2014). El futuro digital. Madrid: Anaya Multimedia.

Suite. M, French. (03 de julio del 2013). Nuevas tecnologías, nuevas adicciones. Recuperado de: http://suite101.net/article/nuevas-tecnologias-nuevas-adicciones-a69539

Turkle, S. (2011).Alone Together: Why we expect more from technology and less from each other. New York: Basic Books.

Universia. (03 de enero del 2011). Uso del BlackBerry puede causar adicción. Recuperado de: $\quad$ http://noticias.universia.net.mx/en-portada/noticia/2011/01/03/776004/usoblackberry-puede-causar-adiccion.html

Valderrama, S. (2002). Pasos para elaborar proyectos de investigación científica ( $\left.1^{\mathrm{a}} \mathrm{ed}\right)$. Lima: San Marcos.

Velezmoro, L. (2007). Relación de los hábitos de lectura con el rendimiento académico de los estudiantes de pregrado de la Universidad de Lima (Tesis de licenciatura). Universidad de Lima.

Vera, R. (12 de noviembre del 2012). El impacto de los Smartphones. Recuperado de: http://ritaaveraa.blogspot.com/ 
ANEXOS 


\section{Anexo 1: Formato de entrevista Semi-Estructurada}

- Cuéntame un poco, ¿Qué sabes sobre los smartphones?

- ¿Qué piensas sobre el uso de los Smartphones? ¿Crees que son útiles?

- ¿Qué haces cuando lo usas? ¿Qué aplicaciones son las que más usas?

- ¿Cuánto tiempo pasas al día usando tu smartphone? ¿Por qué?

- ¿Hay momentos en los que lo apagas o te desconectas voluntariamente? ¿Cuándo?

- ¿Cuánto tiempo crees que podrías estar sin tu Smartphone? ¿Cómo te sentirías?

- ¿El pensar que podría faltarte en algún momento, cómo te hace sentir?

- ¿Cómo crees que sería tu vida sin Smartphone?

- ¿Qué sucedería si estás manejando y tu Smartphone te alerta de que alguien te ha escrito, contestas? ¿Qué pasaría si no pudieras contestarlo? ¿Cómo te sentirías y que pensarías?

- ¿Si llegara un mensaje a la mitad de la noche, te levantarías a contestarlo? ¿Por qué?

- ¿Podrías apagar tu smartphone en horas de clase o de trabajo?

- Si ves que tu smartphone se ha quedado sin batería en medio de la clase, ¿Qué haces, lo pones a cargar inmediatamente, o puedes esperar a salir de clase para cargarlo?

- ¿Al utilizar las redes sociales a través de tu smartphone, crees que te permite comunicar cosas que no te atreverías en persona?

- ¿Cómo qué clase de cosas prefieres decir a través del Smartphone, en vez de decirlas en persona?

- Cuando debes tomar una decisión y no sabes que hacer, ¿tiendes a publicar tu preocupación en alguna de las redes sociales a través de tu Smartphone para pedir opiniones, o guiarte en lo que debes hacer?

- ¿Cómo consideras que se relaciona el uso de smartphones con tu vida universitaria?

- ¿En horas de clase usas tu smartphone? ¿Lo haces mientras estás estudiando?

- ¿Cuántas horas al día crees que pasas "conectado" en relación a tus horas de estudio? ¿Por qué/Para qué?

- ¿Sientes que este ayuda o interfiere en tu vida universitaria? ¿Por qué?

- ¿Aplazas o aceleras tu estudio por estar conectado con tu Smartphone?

- ¿Te es difícil concentrarte mientras estudias cuando tienes tu smartphone al lado? 
- ¿Pierdes mucho tiempo académico (de estudio, trabajos, etc) por usar tu smartphone?

- ¿Estudiar te toma más tiempo debido al uso constante que le das al smartphone?

- Desde que usas tu smartphone, tu promedio: ¿se ha mantenido, ha bajado, o ha subido?

- ¿Si tienes que realizar un trabajo, prefieres buscar información desde tu smartphone en vez de buscar libros? ¿Piensas que es suficiente la información que puedes obtener desde tu smartphone para realizar trabajos académicos?

- ¿Alguna vez has llegado tarde a clase por haber estado distraído con tu smartphone?

- ¿Te has perdido de alguna explicación importante por utilizarlo?

- ¿Alguna vez te han llamado la atención en clase por estar usando tu smartphone?

- ¿Alguna vez has preferido no entrar a clase por estar en una conversación interesante mediante tu smartphone?

- ¿Usar tu smartphone impide que cumplas tus trabajos en el plazo que te has propuesto?

- ¿Podrías rendir en la universidad, mejor o peor sin tu Smartphone, qué piensas? ¿Por qué?

- Si en caso estuvieras en una explicación de clase importante y ves que te ha llegado un mensaje, ¿Podrías esperar al final de la clase para revisarlo?

- ¿Revisas tu smartphone en horas de clase?

- ¿Conversas con tus compañeros de clase en hora de clase mediante éste?

- ¿Juegas mediante tu smartphone en horas de clase?

- ¿En qué momentos juegas más? ¿Qué juegas?

- Si lo usas en horas de clase, ¿lo usas para conversar, jugar o buscar alguna información académica? 


\section{Anexo 2: Libro de Códigos}

\section{LIBRO DE CÓDIGOS: SMARTPHONES}

\section{CATEGORIA 1 : UTILIDAD}

SUBCATEGORÍA 1.1

SUBCATEGORIA 1.2

SUBCATEGORIA 1.3

SUBCATEGORIA 1.4

SUBCATEGORIA 1.5

SUBCATEGORIA 1.6

Académica

Comunicación

Lúdica

Uso de aplicaciones adquiridas

Herramientas propias del Smartphone

Laboral

\section{CATEGORIA 2 : DEPENDENCIA}

SUBCATEGORÍA 2.1

SUBCATEGORÍA 2.2

SUBCATEGORÍA 2.3

Tiempo

Momento

Rapidez de conexión

\section{CATEGORIA 3 : SENSACIÓN AL SEPARARSE DEL SMARTPHONE}

SUBCATEGORÍA 3.1

SUBCATEGORÍA 3.2

SUBCATEGORÍA 3.3

SUBCATEGORÍA 3.4

SUBCATEGORÍA 3.5

SUBCATEGORÍA 3.6

Aislamiento

Desesperación

Ansiedad

Frustración

Ausencia

Estrés

\section{CATEGORIA 4 : RELACION CON EL INTERLOCUTOR}

SUBCATEGORÍA 4.1

Fácil

SUBCATEGORÍA 4.2

Indiferente

\section{CATEGORIA 5 : INTERFERENCIA}

SUBCATEGORÍA 5.1

SUBCATEGORÍA 5.2
Académica

Laboral

\section{CATEGORIA 6 : RENDIMIENTO ACADEMICO}

SUBCATEGORÍA 6.1

SUBCATEGORÍA 6.2
Percepción del rendimiento académico

Promedio académico

\section{CATEGORIA 7 : TEMATICA A TRAVES DEL SMARTPHONE}

SUBCATEGORÍA 7.1

SUBCATEGORÍA 7.2
Personal

Cotidiana 


\section{Anexo 3: Ficha de Consentimiento}

\section{FICHA DE CONSENTIMIENTO}

El propósito de esta ficha de consentimiento es proveer al participante en esta investigación una clara explicación de la naturaleza de la misma, así como de su rol en ella como participante.

La presente investigación es conducida por de la Universidad La meta de este estudio es

Si usted accede a participar en este estudio, se le pedirá responder preguntas en una entrevista (o completar una encuesta, tests o lo que fuera según sea el caso). Esto tomará aproximadamente minutos de su tiempo. Lo que conversemos durante estas sesiones se grabará, de modo que el investigador pueda transcribir después las ideas que usted haya expresado.

La participación es este estudio es estrictamente voluntaria. La información que se recoja será confidencial y no se usará para ningún otro propósito fuera de los de esta investigación. Sus respuestas al cuestionario y a la entrevista serán codificadas usando un número de identificación y por lo tanto, serán anónimas. Una vez trascritas las entrevistas, las grabaciones o videos se destruirán.

Si tiene alguna duda sobre este proyecto, puede hacer preguntas en cualquier momento durante su participación en él. Igualmente, puede retirarse del mismo en cualquier momento sin que eso lo perjudique en ninguna forma. Si alguna de las preguntas durante la entrevista le parecen incómodas, tiene usted el derecho de hacérselo saber al investigador o de no responderlas.

Desde ya le agradecemos su participación.

Acepto participar voluntariamente en esta investigación, conducida por . $\mathrm{He}$ sido informado (a) de que la meta de este estudio es

Me han indicado también que tendré que responder cuestionarios, tests y preguntas en una entrevista, lo cual tomará aproximadamente minutos.

Reconozco que la información que yo provea en el curso de esta investigación es estrictamente confidencial y no será usada para ningún otro propósito fuera de los de este estudio sin mi consentimiento. He sido informado de que puedo hacer preguntas sobre el proyecto en cualquier momento y que puedo retirarme del mismo cuando así lo decida, sin que esto acarree perjuicio alguno para mi persona. De tener preguntas sobre mi participación en este estudio, puedo contactar a al teléfono

Entiendo que una copia de esta ficha de consentimiento me será entregada, y que puedo pedir información sobre los resultados de este estudio cuando éste haya concluido. Para esto, puedo contactar a al teléfono anteriormente mencionado. 